\title{
On the interplay of microstructure and residual stress in LPBF IN718
}

Itziar Serrano-Munoz ${ }^{1, *}$ (D), Tobias Fritsch ${ }^{1}$, Tatiana Mishurova ${ }^{1}$, Anton Trofimov $^{1,2}$, Daniel Apel ${ }^{3}$, Alexander Ulbricht ${ }^{1}$, Arne Kromm ${ }^{1}$, René Hesse ${ }^{1}$, Alexander Evans ${ }^{1}$, and Giovanni Bruno ${ }^{1,4}$

${ }^{1}$ Bundesanstalt für Materialforschung und -prüfung (BAM), Unter den Eichen 87, 12205 Berlin, Germany

${ }^{2}$ Department of Mechanical Engineering, Ecole Polytechnique de Montreal, Chemin de la Rampe, Montreal, QC 5155 H3S 5G4, Canada

${ }^{3}$ Helmholtz-Zentrum Berlin für Materialien und Energie GmbH, Hahn-Meitner Platz 1, 14109 Berlin, Germany

${ }^{4}$ Institute of Physics and Astronomy, University of Potsdam, Karl-Liebknecht-Str. 24-25, 14476 Potsdam, Germany

Received: 22 June 2020

Accepted: 9 November 2020

Published online:

25 December 2020

(C) The Author(s) 2020

\section{ABSTRACT}

The relationship between residual stresses and microstructure associated with a laser powder bed fusion (LPBF) IN718 alloy has been investigated on specimens produced with three different scanning strategies (unidirectional Y-scan, $90^{\circ}$ $\mathrm{XY}$-scan, and $67^{\circ}$ Rot-scan). Synchrotron X-ray energy-dispersive diffraction (EDXRD) combined with optical profilometry was used to study residual stress (RS) distribution and distortion upon removal of the specimens from the baseplate. The microstructural characterization of both the bulk and the nearsurface regions was conducted using scanning electron microscopy (SEM) and electron backscatter diffraction (EBSD). On the top surfaces of the specimens, the highest RS values are observed in the Y-scan specimen and the lowest in the Rot-scan specimen, while the tendency is inversed on the side lateral surfaces. A considerable amount of RS remains in the specimens after their removal from the baseplate, especially in the Y- and Z-direction (short specimen dimension and building direction (BD), respectively). The distortion measured on the top surface following baseplate thinning and subsequent removal is mainly attributed to the amount of RS released in the build direction. Importantly, it is observed that the additive manufacturing microstructures challenge the use of classic theoretical models for the calculation of diffraction elastic constants (DEC) required for diffraction-based RS analysis. It is found that when the Reuß model is used for the calculation of RS for different crystal planes, as opposed to the conventionally used Kröner model, the results exhibit lower scatter. This is discussed in context of experimental measurements of DEC available in the literature for conventional and additively manufactured Ni-base alloys.

Handling Editor: Sophie Primig.

Address correspondence to E-mail: itziar.serrano-munoz@bam.de 


\section{Introduction}

Inconel 718 (IN718) is a Ni-based superalloy with widespread application at high temperatures (up to $650{ }^{\circ} \mathrm{C}$ ) and corrosive environments such as those encountered in gas turbines, due to an excellent combination of strength, resistance to oxidation and corrosion, favourable weldability, as well as good fatigue and creep properties [1]. Nevertheless, the low thermal conductivity and high hardness of IN718 pose limitations to the use of conventional forming processes. The use of additive manufacturing (AM) techniques can greatly resolve these limitations [2, 3], offering the advantages of increasing design complexity and cost saving via the optimization of material usage.

The AM process parameters highly influence the resulting microstructure, the level of residual stress (RS) and the defect content. In particular, the scanning strategies have a remarkable effect on the solidification texture as they control the directionality of the heat flux [4]. Also, the cooling rates at the melt pool can lead to columnar, mixed, or equiaxed grain growth depending on the scanning strategy used [5]. The columnar grains are usually formed with the longest axis parallel to the building direction (BD). Note that the cooling rates induced in the bulk are not usually the same at the free surfaces, which tend to develop equiaxed grains regardless of the technique, material, and process parameter utilized [6-8].

Laser powder bed fusion (LPBF) is an AM technique whereby a thin layer of metallic powder under an inert gas atmosphere is selectively melted via a high energy laser beam. This technique is known to introduce high magnitudes of internal stresses that, when uncontrolled, may lead to specimen cracking, RS, and distortion [9-11]. RS are inhomogeneous selfequilibrating stresses (and moments) present in a body in the absence of external forces, temperature gradients, or moments. They appear whenever a material experiences a heterogeneous inelastic strain such as when the material is plastically deformed in a non-uniformly manner [12]. The residual stresses are often defined by the length scale over which they balance. The long-range macro-stress (termed Type I) equilibrates over the whole body (e.g. over a component). The shorter-range micro-stresses, intergranular (Type II) and intragranular (Type III) balance over many grains or over a single grain or part of a grain, respectively. The current study focuses on the long-range macro-stresses (i.e., Type I).

The principal mechanisms controlling the residual stress build-up during LPBF have been described to be twofold [3, 13]: (i) the temperature gradient mechanism (TGM), which refers to the induced stresses and strain occurring locally in the laser-beam irradiated area; and (ii) the cool-down phase mechanism, which accounts for the shrinkage mismatch between the previously melted material and the solidifying layer. In the general case, the resulting RS fields tend to be tensile at the surface and compressive in the bulk. This trend has also been observed in LPBF IN718 alloys, where tensile RS close to the yield strength has been observed at the surface regions, while the bulk exhibits compressive RS magnitudes of lower magnitudes than the tensile ones [14-16].

One of the widely adopted RS mitigation strategies consists of adapting the scanning strategies in order to homogenize and reduce thermal stresses during the process [17-19]. For example, unidirectional scanning strategies localize the heat over the same path upon deposition of successive layers. Moreover, using a scanning vector parallel to the longest dimension of a specimen leads to steeper thermal gradients. On the other hand, an interlayer alternation in the direction of the scan-vector reduces the heat concentration at a particular location. In this regard, a $67^{\circ}$ interlayer avoids the repetition of the scan-vector direction for a maximum number of layers and it has been reported to reduce distortion, anisotropy, and surface roughness [20].

In LPBF, the surface roughness principally varies depending on the process parameters and on the orientation of the build direction with respect to the recoating blade [21-23]. The surface roughness severity is a limiting factor when measuring surface and near-surface RS since it locally relaxes the stress, creating gradient of increasing stress towards the interior [24, 25]. Thus, the influence of the process parameters (in our case the scanning strategy) on the surface roughness needs to be considered when measuring surface/near-surface RS.

In spite of the considerable amount of work reported so far on the characterization of AM IN718 alloys, there are still some remaining uncertainties due to the limited reproducibility, predictability, and microstructural complexity of the resulting products. These uncertainties have a considerable influence on 
the interpretation of results, sometimes invalidating comparisons among available literature sources. Moreover, the coarse-grained and strongly textured microstructures, which can be characteristic of certain AM processes or scanning strategies, pose a challenge to data analysis when using diffraction-based techniques. For instance, the chosen diffraction elastic constants (DEC, used for the connection between the diffraction measured micro-strain and the macrostress) can lead to significant variations of the calculated residual stress [26]. The correct determination of the magnitude of residual stresses is expected to be crucial for the understanding of the mechanical performance of components. In this regard, the DEC measured in a LPBF Ti-6Al-4V alloy have been already reported to deviate from the DEC values of conventionally produced Ti-6Al-4V [27]. Note that the need to assess the validity of conventional DEC is not exclusive to AM materials, since this requirement is valid for any new material exhibiting unconventional microstructures.

The classic theoretical models of Voigt, Reuß, and Kröner continue to be used to calculate the DEC for the RS analysis from diffraction data. The Voigt model represents a limiting case whereby each different grain has the same strain [28]. It is generally to be avoided for the calculation of RS in materials with high anisotropy since it does not take elastic anisotropy of the various hkl reflections into account. The Reuß model represents another limiting case and assumes that the stress is constant between grains [29]. Crystallites in a polycrystalline aggregate develop strains proportional to the anisotropic modulus for their particular orientation. The Kröner model allows both stresses and strains to vary between grains that have arbitrary orientations. It takes advantage of the Eshelby inclusion model to calculate the overall stiffness of a grain embedded in a continuum matrix, which is exposed to a specific homogeneous stress field [30, 31]. Introduction to these models can be found in textbooks such as $[26,32]$. Many efforts have been and continue to be dedicated to the improvement of the fundamental models [33-35]. Such improvements have been directed to include the effect of texture.

With this view, we consider that two fundamental points are so far missing in the AM literature: (i) the textured microstructures resulting from AM necessitates a redefinition of the diffraction elastic constants (DEC) used for the calculation of macro-stresses; and (ii) the formation of RS and microstructure are so far addressed in the literature as two independent results from the selection of the scanning strategy: we propose that in fact they are interconnected, and that this relationship needs to be studied in further detail. In this regard, a previous work by the authors has shown that highly textured columnar grains (i.e., anisotropic grain structure), as opposed to mildly textured elongated grains, can more easily accumulate strain dislocations along the building direction, which is considered to lead to increased RS relaxation [25].

The present work compares the near-surface RS state and degree of distortion upon removal from the baseplate of a LPBF IN718 material produced using different scanning strategies. The studied interlayer scanning strategies are Y-unidirectional (corresponding to the shortest XY-plane direction), XY-alternation, and $67^{\circ}$-rotation. The investigation was conducted by combining laboratory $X$-ray diffraction (LXRD), synchrotron X-ray energy-dispersive diffraction (EDXRD), and optical profilometry techniques. Detailed characterization of the microstructure via scanning electron microscope (SEM), energydispersive spectroscopy (EDS), and electron backscatter diffraction (EBSD) allowed further interpretation of the EDXRD results. The pertinence of using the Reuß model instead of the Kröner model for AM materials is evaluated. Finally, the differences in microstructure and RS states as a function of the scanning strategy are discussed.

\section{Materials and experimental methods}

\section{Materials and processing}

The specimens were supplied by Siemens AG, Power and Gas Division, Berlin, Germany. The manufacturing was performed using an EOS M290 machine in an argon atmosphere with low level of oxygen to avoid oxidation. An IN718 pre-allowed powder was used entirely in a virgin (not recycled) condition and the powder layer thickness was $40 \mu \mathrm{m}$. Figure 1a-c shows the three scanning strategies investigated in the present work. Note that the three studied specimens were produced in the same build job, have the same orientation with respect to the recoater and the inert gas flow, and are aligned at different positions along the Y-axis. The hatching stripe (HS) width 


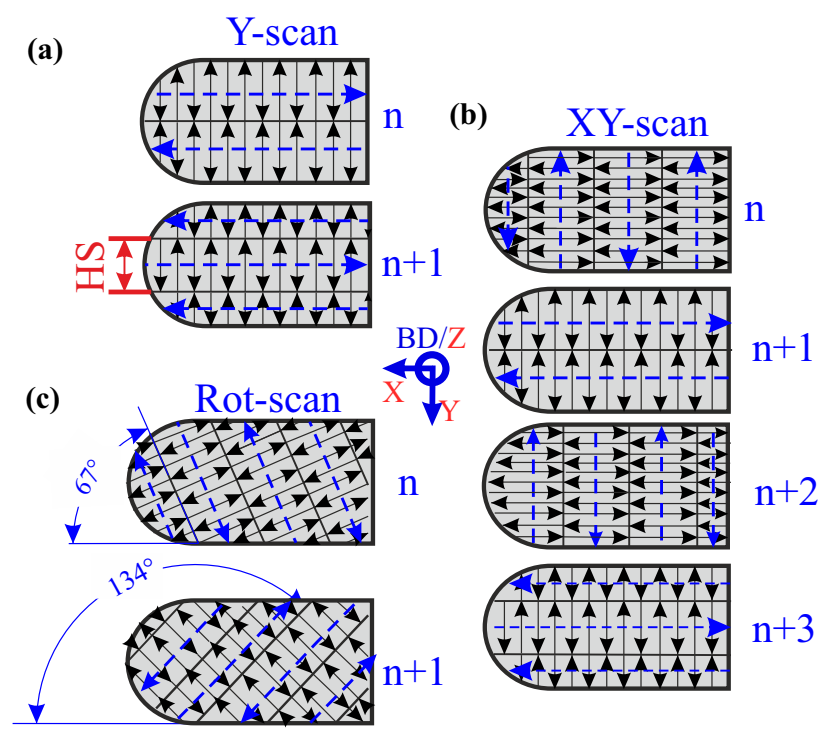

(d)

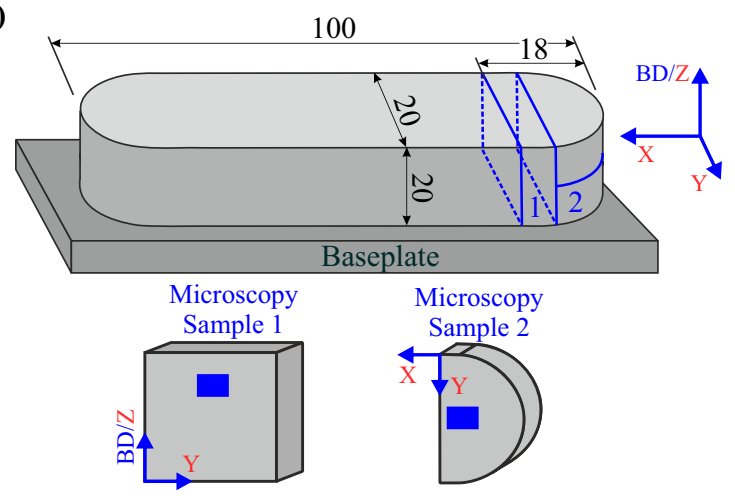

Figure 1 Schematic illustration of the studied scanning strategies corresponding to $\mathbf{a}$ the $\mathrm{Y}$-scan specimen, $\mathbf{b}$ the $\mathrm{XY}$-scan specimen, and $\mathbf{c}$ the Rot-scan specimen. The black arrows indicate the rastering directions and the blue arrows the direction of advancement of the rastering within each strip. d Illustration showing the specimen geometry (units in millimetres) and the location where the microscopy samples were extracted (top). The location of the microstructural observations (SEM, EBSD, EDS) is shown at the bottom.

corresponds to $1 / 10$ of the length of the specimens (in the $\mathrm{X}$-direction). The specimen dimensions are $100 \times 20 \times 20 \mathrm{~mm}^{3} \quad$ (see Fig. 1d). The building direction (BD) corresponds to the $\mathrm{Z}$ axis. The top surface of all the specimens was subjected to an upskin process (corresponding to the last three layers, $\sim 120 \mu \mathrm{m}$ ), where the volumetric energy density was $4 \%$ lower than that applied to the rest of the specimen. The remaining process parameters are proprietary to Siemens AG and cannot be disclosed. The nominal yield strength in the as-fabricated condition is $\sigma_{\mathrm{y} / / \mathrm{BD}}=632 \mathrm{MPa}$ (parallel to the $\mathrm{Z} / \mathrm{BD}$-direction) and $\sigma_{\mathrm{y} \perp \mathrm{BD}}=806 \mathrm{MPa}$ (perpendicular to the build direction). These values are similar to those reported in the literature [36, 37].

\section{Microscopy}

Microstructural characterization of the specimens was performed using a LEO 1530VP (ZEISS) scanning electron microscope (SEM) equipped with an electron backscatter diffraction (EBSD) Bruker Nano e-Flash HD 5030 detector, as well as an energy-dispersive spectroscopy detector (EDS, XFlash 5030). The SEM was operated at an acceleration voltage and beam current of $20 \mathrm{kV}$ and $\approx 7 \mathrm{nA}$, respectively. The ESPRIT 1.94 package from Bruker Nano was used for data collection and pattern indexing. Post-processing was performed using MTEX software [38]. The microscopy samples (see Fig. 1d) were prepared using standard metallographic grinding and polishing. The final polishing was achieved using $0.02 \mu \mathrm{m}$ colloidal silica suspension.

Note that the microscopy samples were extracted from one end of the specimen. This extraction was conducted while the specimens were still attached to the $36 \mathrm{~mm}$ thick baseplate. It has been shown that this sectioning has a negligeble effect on the RS state of the other end of the specimen [39].

\section{Laboratory X-ray diffraction (LXRD)}

The specimens were examined in three conditions: (i) the As-Built condition, corresponding to the state with the original baseplate thickness $(36 \mathrm{~mm}$ ), (ii) the Thin-Baseplate condition, corresponding to the state after baseplate thinning to $6 \mathrm{~mm}$ thickness, and (iii) the Released condition, corresponding to the state where the baseplate was completely removed from the specimen. Both the thinning of the baseplate and the removal of the specimens from baseplate were performed using electro-discharge machining (EDM). Note that the use of the LXRD technique was confined to study the effect of the baseplate thinning on the top surfaces along a central line parallel to the X-direction.

The surface RS analysis was performed using a Xstress G3 diffractometer (StressTech, Vaajakoski, Finland). This instrument works in angular dispersive (AD) X-ray diffraction mode and is equipped with a movable arm carrying an X-ray source and 
two position-sensitive detectors that revolve around a stationary specimen. $\mathrm{A} \mathrm{MnK}_{\alpha}$ radiation source was used with a collimator aperture of $2 \mathrm{~mm}$ in diameter. The exposure time for each recording was $5 \mathrm{~s}$. The penetration depth of the X-ray laboratory source in $\mathrm{Ni}$ is estimated to be $\sim 5 \mu \mathrm{m}$. The Ni-311 reflection $\left(2 \theta=156^{\circ}\right)$ was measured in an angular tilt range from $\psi=-45^{\circ}$ to $\psi=45^{\circ}$ with a total of 19 steps. The acquired data were processed with the software Xtronic and the Pearson VII function was used for the peak fitting. The RS was calculated using the $\sin ^{2} \psi$ method with the elastic constants for Ni-311 reflection calculated by the Reuß model (Young's modulus of $178 \mathrm{GPa}$ and Poisson's ratio of 0.34 ).

\section{Synchrotron X-ray energy-dispersive diffraction (EDXRD)}

Near-surface RS analysis was performed at the EDDI beamline [40], at the synchrotron facility BESSY II (Helmholtz Zentrum Berlin (HZB), Germany). This beamline operated in energy-dispersive mode and provided a white beam with an energy range of about $10 \mathrm{keV}-150 \mathrm{keV}$. Apart from the increased penetration power due to the higher X-ray energies available, the advantage of energy-dispersive (ED) diffraction compared to angle dispersive (AD) is the data acquisition. Only single line profiles are usually measured in the AD mode for set-ups with fixed positions of both specimen and detector. On the other hand, the ED mode of diffraction gives complete diffraction spectra with a multitude of reflections for the equivalent set-up (i.e., fixed scattering vector). The fact that each reflection corresponds to different $X$-ray energies leads to the measurement of a depthresolved residual stress profile.

The RS state (corresponding to Type I stresses) was investigated by mapping the equivalent regions on the top surfaces and one of the lateral surfaces (termed Surface 1) of all the specimens (see Fig. 2a). The reflection-mode measurements were taken with the specimens mounted on an Euler cradle. Since this cradle could not carry more than $5 \mathrm{~kg}$, only the ThinBaseplate and Released conditions were investigated with EDXRD (Fig. 2b). The diffraction angle was set at $2 \theta=10^{\circ}$ for all experiments (Fig. 2c). The prismatic sampling gauge volume was defined by the intersection of the incoming beam (defined by slits with a vertical and horizontal opening of $H_{\mathrm{v}}=1 \mathrm{~mm}$ and $H_{\mathrm{h}}=1 \mathrm{~mm}$, respectively) and the diffracted beam (the secondary slits vertical opening is $H_{\mathrm{d}}=30 \mu \mathrm{m}$ ). The effective gauge volume (corresponding to the immersed volume) length was $L_{\mathrm{GV}}^{\mathrm{eff}}=5.9 \mathrm{~mm}$. The detector was a liquid-nitrogen cooled Ge solid-state detector from Canberra (model GL0110). The counting time was $2.5 \mathrm{~min}$ per spectrum.

Since the measurements were taken in the nearsurface region using the reflection mode, the stress component normal to the investigated surfaces could be assumed to be zero (biaxial plane stress state). Full diffraction patterns were acquired at nine $\psi$ angles. The lattice strain $\left(\varepsilon_{\varphi \psi}\right)$ in the $\varphi$ and $\psi$ directions is defined according to:

$\varepsilon_{0^{\circ} \psi}=1 / 2 S_{2} * \sigma_{0^{\circ}} * \sin ^{2} \psi+S_{1} *\left(\sigma_{\mathrm{X}}+\sigma_{\mathrm{Y}}\right)=\frac{d_{0^{\circ} \psi}-d_{0}}{d_{0}}$

(a)
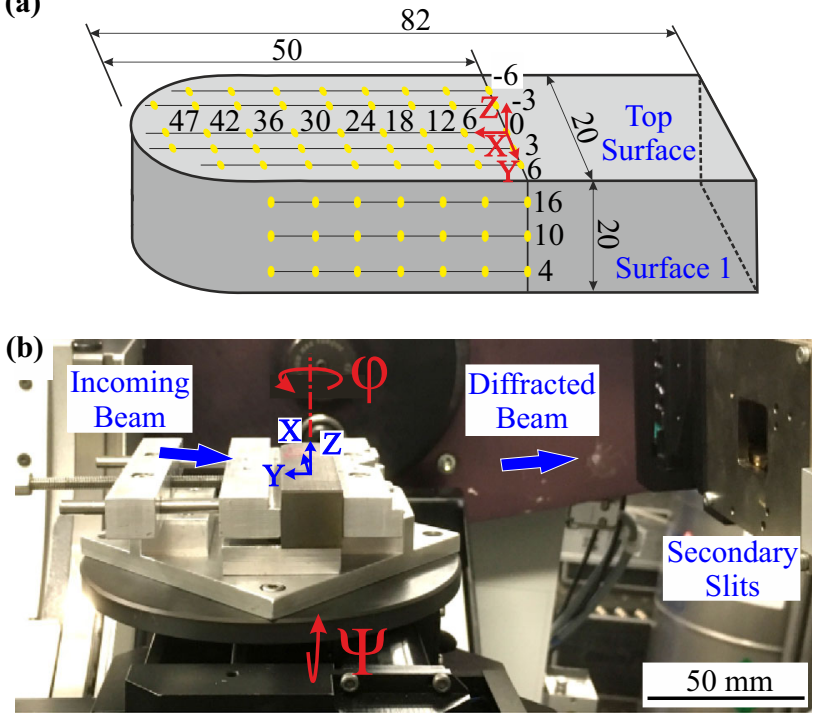

(c)

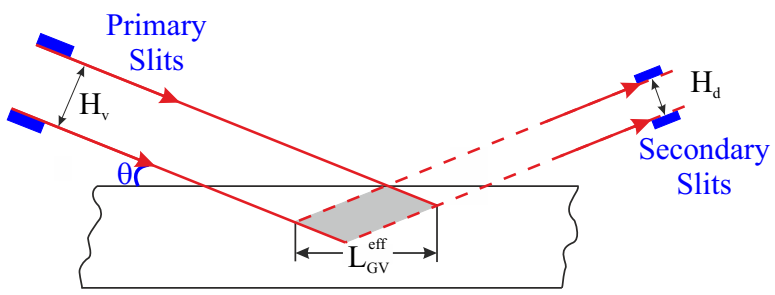

Figure 2 a Illustration of the location of the EDXRD measurement points, as well as the specimen coordinate system (units in $\mathrm{mm}$ ). $\mathbf{b}$ Image of the reflection set-up at EDDI beamline corresponding to the $\varphi=90^{\circ}$ and $\psi=0^{\circ}$ positioning of one of the investigated specimens. $c$ Schematic illustration of the diffraction information area (in grey) corresponding to the set-up utilized during the measurements. 


$$
\begin{aligned}
\varepsilon_{90^{\circ} \psi} & =1 / 2 S_{2} * \sigma_{90^{\circ}} * \sin ^{2} \psi+S_{1} *\left(\sigma_{\mathrm{X}}+\sigma_{\mathrm{Y}}\right) \\
& =\frac{d_{90^{\circ} \psi}-d_{0}}{d_{0}}
\end{aligned}
$$

where $\varphi=0^{\circ}$ and $\varphi=90^{\circ}$ correspond to the $\mathrm{Y}$ and $\mathrm{X}$ principal components in the Top Surface, respectively, $S_{1}$ and $1 / 2 S_{2}$ are the diffraction elastic constants (DEC) [32], and $d_{0}$ is the unstrained interplanar lattice spacing. The assumption of a plane stress state supersedes the need for an accurate $d_{0}$ value. Since $d_{0}$ is simply a multiplying factor of the linear regression slope when calculating $\sigma_{\varphi}$, it can be approximated by the value measured at zero degrees, $d_{\varphi, \psi=0^{\circ}}$, giving rise to errors in the stress of only fractions of a percent. In addition, $d_{\varphi \psi}$ is the interplanar spacing measured in the direction described by angles $\varphi$ and $\psi[26]$. The DEC used in this study correspond to the Reuß model [29] and are shown in Table 1 (see also the discussion section).

Based on the $d_{\psi}^{\mathrm{hkl}}-\sin ^{2} \psi$ linear regression, RS values can be calculated through the following relation: $\sigma_{\varphi}=\frac{m}{1 / 2 S_{2}}$,

where $m$ is the slope of the linear regression. When using the $\sin ^{2} \psi$-method, the information depth to which the measured diffraction signal can be assigned is defined by:

$\tau_{\psi}^{\mathrm{hkl}}=\frac{\sin \theta}{2 \mu\left(E^{\mathrm{hkl}}\right)} * \cos \psi$,

where $\mu\left(E^{h k l}\right)$ is the energy-dependent linear absorption coefficient. The maximum information depth is achieved at $\psi=0$ and denoted $\tau_{0}^{\text {hkl }}$ hereafter. The Laplace methods are used to obtain the depth

Table 1 Plane-specific DEC values of the Reuß model corresponding to the Ni crystal

\begin{tabular}{llc}
\hline $\mathrm{hkl}$ & $S_{1}, \mathrm{MPa}^{-1} \times 10^{-6}$ & $1 / 2 S_{2}, \mathrm{MPa}^{-1} \times 10^{-6}$ \\
\hline 111 & -0.763 & 4.1 \\
200 & -2.94 & 10.6 \\
220 & -1.31 & 5.73 \\
311 & -1.92 & 7.56 \\
400 & -2.94 & 10.6 \\
331 & -1.15 & 5.26 \\
420 & -1.9 & 7.5 \\
\hline
\end{tabular}

resolution of each hkl reflection directly from the exponential beam attenuation law for X-rays when passing through matter [41]. All the RS maps shown in the results section correspond to the crystallographic plane (311). This plane was chosen because of its low plastic anisotropy in conventional Ni-base alloys [42]. Note that we generated $\sigma-\tau_{0}^{\text {hkl }}$ plots, instead of generating them with the average $\left\langle\tau^{\mathrm{hkl}}\right\rangle$, as recommended in [43]; this led to a discrete depth distribution, which coincides with the actual Laplace stress depth. For the 311 reflection, the maximum information depth is $\tau_{0}^{311}=42 \mu \mathrm{m}$. The EDDIDAT program system provided by the X-ray CoreLab (HZB) [44] was used for handling the measured data and stress calculation.

In order to compare RS with distortions, Von Mises (VM) stresses were calculated for the Top Surface, according to:

$\sigma_{\mathrm{VM}}=\sqrt{\sigma_{\mathrm{X}}^{2}-\sigma_{\mathrm{X}} \sigma_{\mathrm{Y}}+\sigma_{\mathrm{Y}}^{2}}$.

Note that both VM RS and distortions are not related to hydrostatic stresses [45].

\section{Distortion and surface roughness evaluation}

The Z-displacement of the upper surface of the specimens (i.e., Top Surface) was measured using a white light (diode emitting between 400 and $3400 \mathrm{~nm}$ ) profilometer (an FRT MicroProf device with an FRT CWL sensor). This device used an interferometer to calculate the distance from the specimen surface to the sensor. The area investigated was $18 \times 60 \mathrm{~mm}^{2}$ using a scanning speed of $794 \mu \mathrm{m} / \mathrm{s}$ and a step size of $20 \mu \mathrm{m}$. The data acquired after removal from the baseplate were post-treated to correct for parallelism defects.

The surface roughness was measured using a Hommel Werke TKL300 system, equipped with a tip of $5 \mu \mathrm{m}$ radius. The surface of the region of interest was $30 \times 8 \mathrm{~mm}^{2}$. Four lines parallel to the $\mathrm{X}$-direction (test length of $\mathrm{L}_{\mathrm{t}}=15 \mathrm{~mm}$ with $\mathrm{L}_{\mathrm{c}}=2.5 \mathrm{~mm}$ of cut off) were measured at $V_{\mathrm{t}}=0.5 \mathrm{~mm} / \mathrm{s}$ from bottom to top with incremental spacings of $X=5 \mathrm{~mm}$ and $Y=2 \mathrm{~mm}$. The roughness values $R_{\mathrm{a}}$ (arithmetic mean height), $R_{\mathrm{z}}$ (maximum height), and $R_{\max }$ (maximum peak height) were calculated using the HOMMEL-ETAMIC software according to ISO:4287:210 [46]. 


\section{Results}

\section{Microstructure}

The as-manufactured microstructures characterized by SEM in backscattered electron (BSE) mode display similar columnar dendritic cells (width between 0.4 and $0.8 \mu \mathrm{m}$ ) for all three scan strategies (see Fig. 3a,b, where, for the sake of brevity, only the Y-scan and Rot-scan microstructures are given). In the case of the Rot-scan microstructure (Fig. 3b), the dendrite cell growth direction varies across the different regions. This indicates that the heat flow locally varies within the melt pool, even though the overall heat flow is expected to be approximately parallel to the building direction, as shown in Fig. 3a.

During the solidification of the melt pool, elemental solutes are ejected to dendrite surfaces leading to the localization of alloying elements around the dendrite-cells. The elemental mapping analysis (Fig. 3c) via EDS indicates that the brighter regions surrounding dendritic cells contain higher concentration of the alloying elements $\mathrm{Nb}, \mathrm{Mo}$, and $\mathrm{Ti}$. The EDS analysis also indicates (not shown in Fig. 3c) that these regions are depleted of $\mathrm{Fe}, \mathrm{Cr}$, and, to a lower extent, $\mathrm{Ni}$. It has been reported that these segregated regions occur at the level of dendritic cells, subgrains (formed by a group of adjacent dendritic cells with
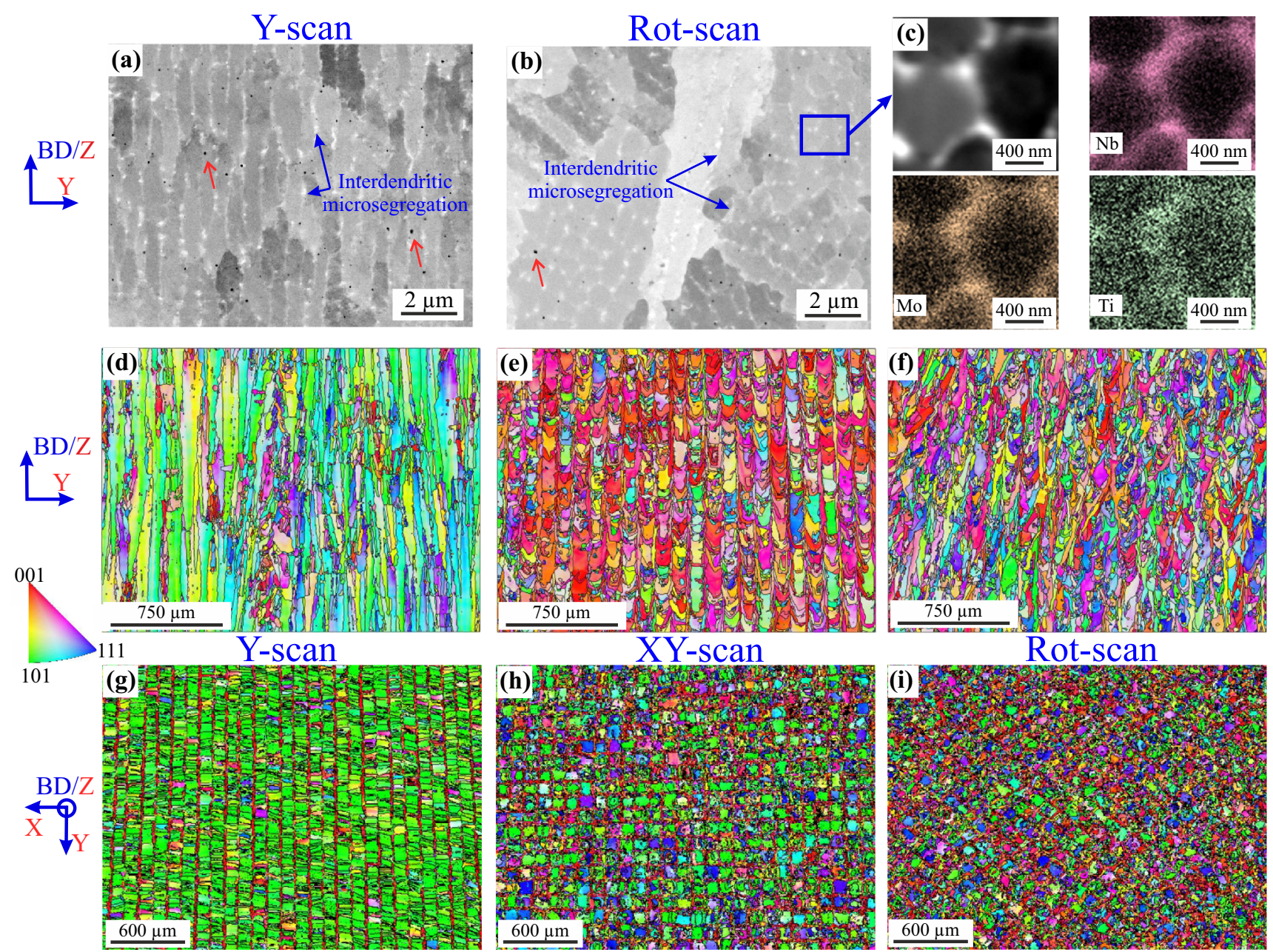

Figure 3 High-magnification backscattered electron (BSE) image of the interdendritic segregation obtained on the ZY-plane of a the $\mathrm{XY}$-scan sample and $\mathbf{b}$ the Rot-scan sample (the red arrows indicate the presence of either aluminium oxides or porosity). c EDS composition maps of some of the alloying elements. Lowmagnification EBSD orientation maps in the ZY-planes of $\mathbf{d}$ the
Y-scan specimen, e the XY-scan specimen, and $\mathbf{f}$ the Rot-scan specimen. Low-magnification EBSD orientation maps on the XYplane of $\mathbf{g}$ the Y-scan specimen (reproduced from [25]), $\mathbf{h}$ the XYscan specimen, and $\mathbf{i}$ the Rot-scan specimen (reproduced from [25]). In all EBSD maps the scattering vector is perpendicular to the images (i.e., conventionally termed IPF-Z maps). 
(a)
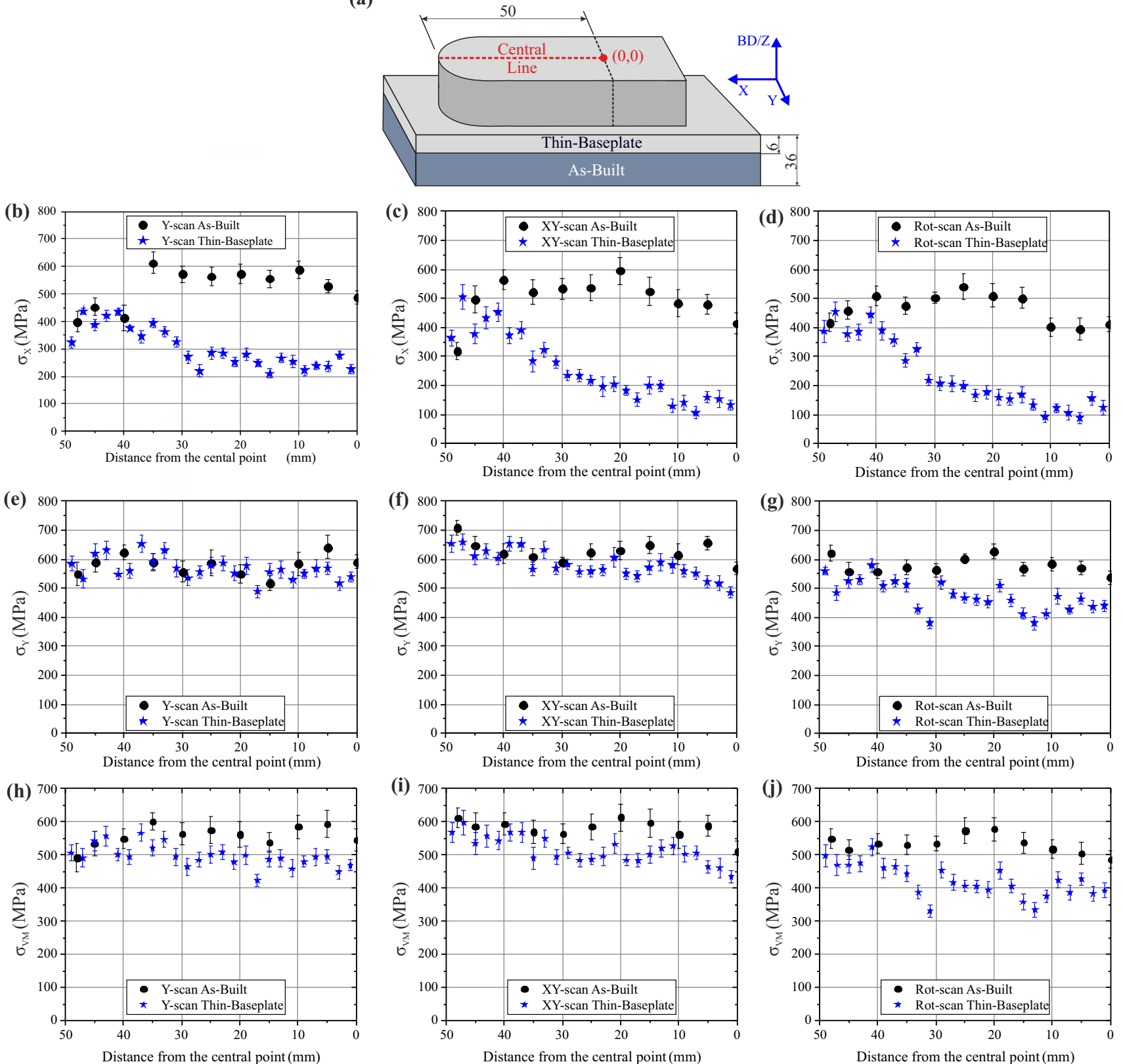

(k)

Thin Baseplate - As Built ( $\mu \mathrm{m})$ $\begin{array}{lllllllll}0 & 10 & 20 & 30 & 40 & 50 & 60 & 70 & 80\end{array}$

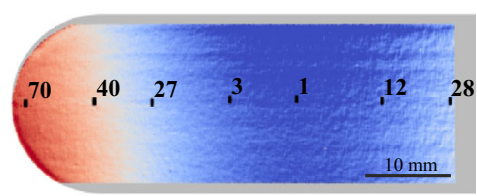

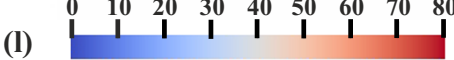

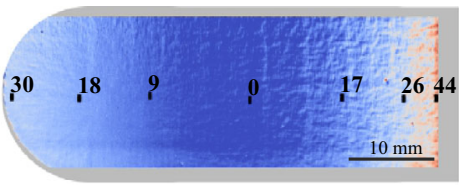

(m)

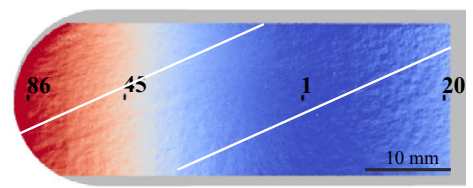


4 Figure 4 a Illustration of the specimen geometry showing the AsBuilt and Thin-Baseplate conditions. RS profiles of the $\mathrm{X}$-direction component before and after baseplate thinning for b the Y-scan specimen (replotted from [25]), c the XY-scan specimen, and $\mathbf{d}$ the Rot-scan specimen (replotted from [25]). RS profiles of the Y-direction component before and after baseplate thinning for $\mathbf{e}$ the Y-scan specimen (replotted from [25]), f the XY-scan specimen, and $\mathbf{g}$ the Rot-scan specimen (replotted from [25]). RS profiles of the Von Mises (VM) component before and after baseplate thinning for $\mathbf{h}$ the $\mathrm{Y}$-scan specimen, $\mathbf{i}$ the XY-scan specimen, and $\mathbf{j}$ the Rot-scan specimen. Distortion maps showing the difference between the As-Built minus Thin-Baseplate conditions for $\mathbf{k}$ the $\mathrm{Y}$-scan specimen, $\mathbf{l}$ the XY-scan specimen, and $\mathbf{m}$ the Rot-scan specimen (the white lines indicate the location of some of the grooves created between hatching stripes). The average error of the LXRD results is $\pm 24 \mathrm{MPa}$.

low angle (about $<5^{\circ}$ ) misorientations), and grain boundaries $[47,48]$. Some authors also report the presence of nanometric Laves $(\mathrm{Ni}, \mathrm{Cr}, \mathrm{Fe})_{2}(\mathrm{Nb}, \mathrm{Ti})$ particles with in these micro-segregated regions [49-53]. The EDS results presented in this study are in agreement with transmission electron microscopy (TEM) observations shown in [54]. Moreover, scanning transmission electron microscopy elemental maps (STEM-EDS) show heterogeneous distributions of alloying elements (notably for $\mathrm{Ti}$ and $\mathrm{Al}$ ), which are in fact related to the presence of Laves $[48,55]$ and carbide phases $\mathrm{MC}(\mathrm{Nb}, \mathrm{Ti})(\mathrm{C}, \mathrm{N})[53,56]$. Finally, the spherical black dots indicated with red arrows in Fig. 3a,b could be either aluminium oxides [57] or gas porosity [53]. It must be noted that our work is focused on the influence of the different grain structures and textures on RS; therefore, a detailed TEM comparison of the micro-segregation is beyond the scope of this article.

The EBSD orientation maps show that the Y-scan specimen developed columnar grains with a dominance of $<101>$-grain orientation (Fig. $3 d$ ). The scanvector direction is clearly noticeable in the XY-plane (Fig. 3g), where thin lines of $<001>$-grains are formed in-between the thicker $<101>$-grain bands. Note that the cluster of purple small grains observed in the centre of Fig. 3d possibly corresponds to one of the thin bands of $<001>$-grains observed in Fig. 3g. The alternating $X Y$-scan also forms columnar grains along the $\mathrm{BD}$, although the dominant grain orientation is $<001>$ and the vertical length of the grain is reduced (Fig. 3e). The scan-vector direction remains noticeable in the XY-plane, but the texture intensity is reduced (Fig. 3 h), with clusters of $<101>$-grains being formed. The Rot-scan specimen exhibits elongated grains (i.e., their aspect ratio is lower than that of columnar grains) with complex shapes and where almost all crystal orientations are observed (Fig. 3f). The XY-plane microstructure appears chaotic in comparison to the other two scanning strategies: the scan-vector direction is barely noticeable and some smaller clusters of $<101>$-grains are observed (Fig. 3i).

\section{LXRD results}

The surface stresses along the central line of one half of the specimens Top Surface are shown in Fig. 4a. These measurement locations correspond to the opposite end of the specimen from where the microscopy samples were extracted. $\sigma_{\mathrm{X}}$ in the AsBuilt condition shows values in the range of 300-650 MPa, with the highest values corresponding to the Y-scan specimen and the lowest to the Rot-scan specimen (Fig. 4b-d). The thinning of the baseplate induces a significant $\sigma_{X}$ relaxation (about $300 \mathrm{MPa}$ ) in the region between 0 and $30 \mathrm{~mm}$. The values at the tip region ( 35 to $50 \mathrm{~mm}$ ) remain close to those observed in the As-Built condition in all specimens. Again, the highest $\sigma_{X}$ values in the Thin-Baseplate condition correspond to the Y-scan specimen ( $\sim 250 \mathrm{MPa}$ against $\sim 150 \mathrm{MPa}$ observed in the Rotscan sample).

The $\sigma_{Y}$ values in the As-Built condition vary from 400 to $700 \mathrm{MPa}$, with the XY-scan specimen having the highest values (by only $50 \mathrm{MPa}$, see Fig. $4 \mathrm{e}-\mathrm{g}$ ) while Y-scan and Rot-scan specimens exhibit similar values. The baseplate thinning does not induce significant RS relaxation in the Y-scan specimen. Nevertheless, a RS relaxation of $\sim 50 \mathrm{MPa}$ and $\sim 100 \mathrm{MPa}$ is observed in the $0-30 \mathrm{~mm}$ region of the XY-scan and Rot-scan specimens, respectively. Note that the $\sigma_{Y}$ profile in the Thin-Baseplate condition exhibits two undulations at 13 and $32 \mathrm{~mm}$ in the Rotscan specimen. These undulations could result from the grooves generated between hatching stripes during processing (see the white lines in Fig. $4 \mathrm{~m}$ ), which would be more noticeable in the Thin-Baseplate condition due to distortion.

When the VM stresses are compared, it is observed that the Rot-scan sample exhibits the highest relaxation (Fig. $4 \mathrm{~h}-\mathrm{j}$ ). This relaxation induces an upward 
bending of the specimens (Fig. $4 \mathrm{k}-\mathrm{m}$ ). The Y-scan and Rot-scan specimens exhibit similar distributions in the distortion maps, although the Z-displacement in the tip region $(35-50 \mathrm{~mm})$ is slightly higher in the Rot-specimen $(10 \mu \mathrm{m}$, which is in agreement with the $\mathrm{VM}$ results). In contrast, the highest measured Z-displacement of the XY-scan specimen occurs near the opposite end of the specimen, with values that are almost half of those recorded in the tip region of the other two specimens.

\section{EDXRD results}

Detailed RS maps of the three principal geometrical components (X, Y, Z(BD)) were obtained for the ThinBaseplate and Released conditions of the XY-scan and Rot-scan specimens. Due to the limited beamtime available on EDDI, the RS state of the Y-scan specimen was not measured in the Released condition. We will see that this does not impact the conclusions of our work. The RS plots in the Thin-Baseplate condition of the Y-scan and Rot-scan specimens are taken from reference [25] for comparison with the $X Y$ scanning strategy, as well as for the study of the relaxation following release from the baseplate. Regardless of the scanning strategy or condition, the $\sigma_{\mathrm{X}}$ stress maps generally exhibit a similar tendency, with the highest values being observed in the tip region (30-47 mm, see Fig. 5). In the Thin-Baseplate condition, the RS values vary over all scan strategies in a range between 50 and $500 \mathrm{MPa}$, with similar distributions in the XY-scan and Rot-scan specimens. In contrast, the Y-scan specimen exhibits higher values (50 MPa on average). The baseplate removal (Released condition) induces a $100 \mathrm{MPa}$ relaxation in the tip region, and the similarity between the XY-scan and Rot-scan specimens is maintained.

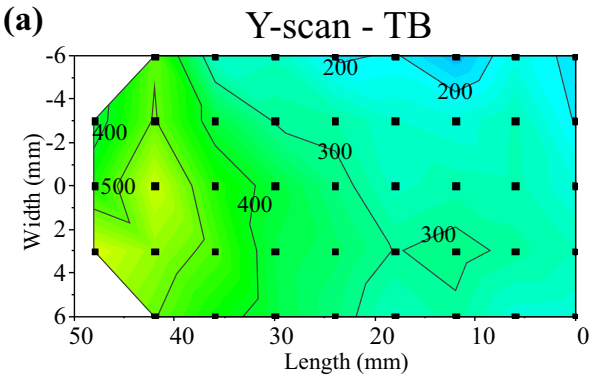

(b)

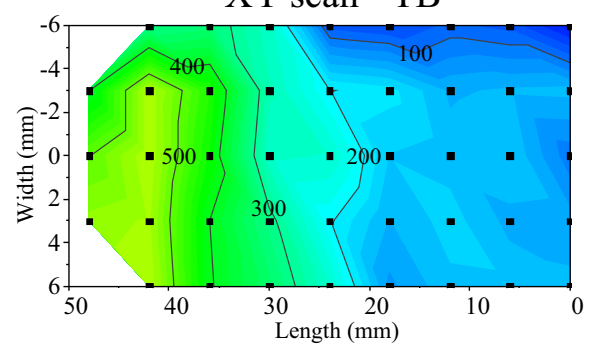

(c)

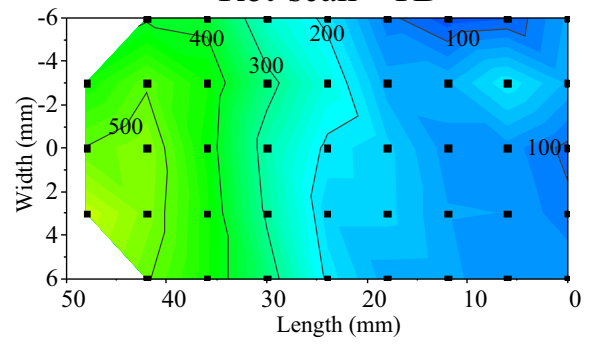

Figure 5 Top Surface RS maps of the X-direction component in the Thin-Baseplate (TB) condition for a the Y-scan specimen (replotted from [25]), $\mathbf{b}$ the XY-scan specimen, and $\mathbf{c}$ the Rot-scan specimen (replotted from [25]). Top Surface RS maps of the
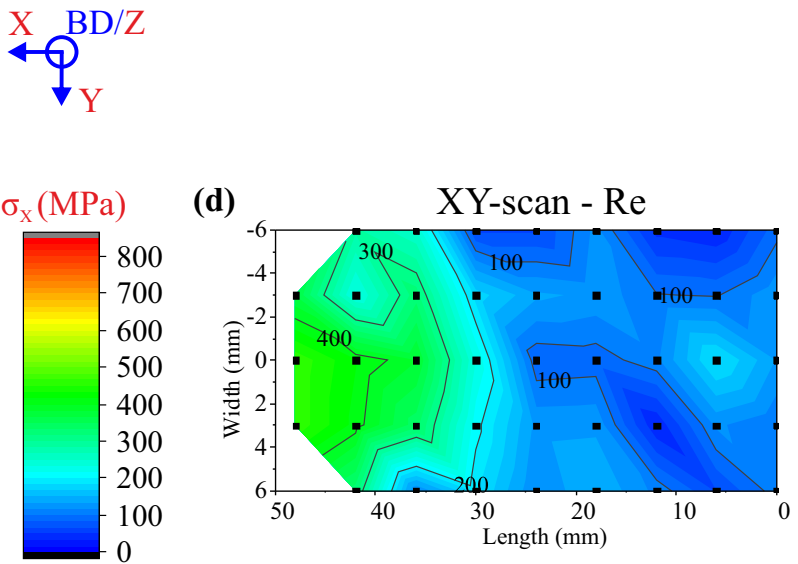

(e)

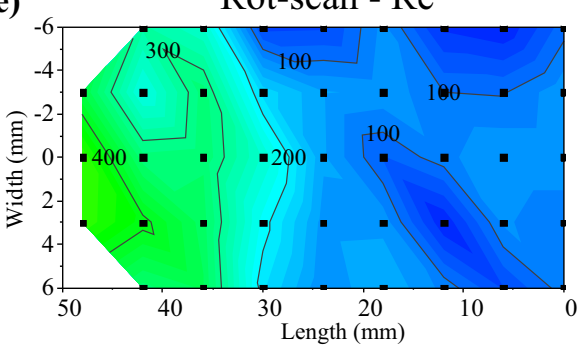

$\mathrm{X}$-direction component in the Released $(\mathrm{Re})$ condition for $\mathbf{d}$ the XY-scan specimen and e the Rot-scan specimen. The small black squares indicate the location of the measurement points. The average error for all the points is $\pm 28 \mathrm{MPa}$. 
(a)
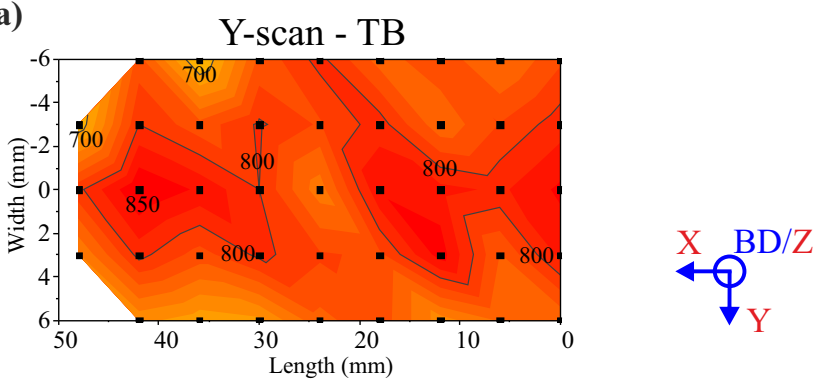

(b)
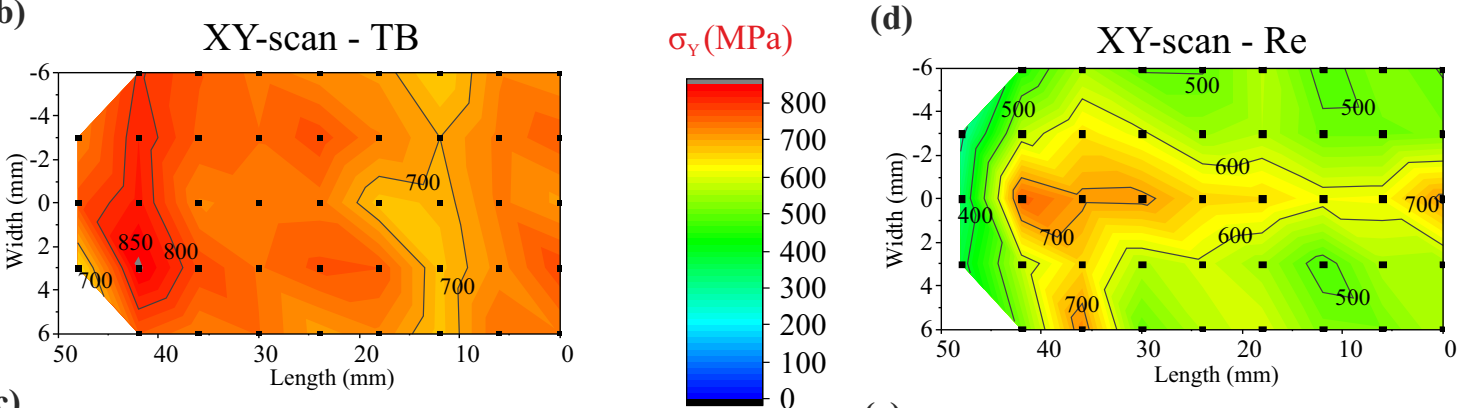

(c)

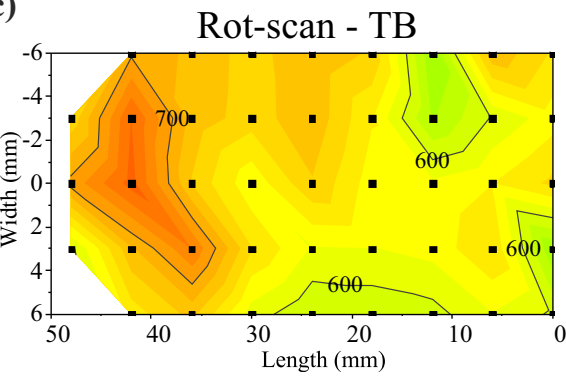

(e)
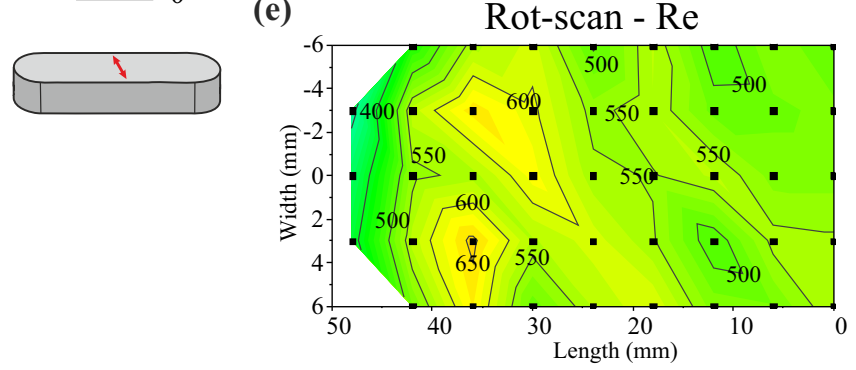

Figure 6 Top Surface RS maps of the Y-direction component in the Thin-Baseplate (TB) condition for a the Y-scan specimen (replotted from [25]), $\mathbf{b}$ the XY-scan specimen, and $\mathbf{c}$ the Rot-scan specimen (replotted from [25]). Top Surface RS maps of the

Y-direction component in the Released ( $R e$ ) condition for $\mathbf{d}$ the $\mathrm{XY}$-scan specimen and $\mathbf{e}$ the Rot-scan specimen. The average error of the points shown in these maps is $\pm 34 \mathrm{MPa}$.

In the $0-25 \mathrm{~mm}$ region for the Thin-Baseplate condition, the highest values also correspond to the Y-scan specimen (100 MPa higher than those of the other two specimens, Fig. 5a). A slight asymmetry with respect to the $\mathrm{X}$-axis is observed, principally in the Y-scan specimen. The stress distributions are also similar in the XY-scan and Rot-scan specimens, with the XY-scan values being slightly higher $(50 \mathrm{MPa}$, Fig. $5 b-c)$. A small stress relaxation $(>50 \mathrm{MPa})$ is observed after the baseplate removal; however, the similarity between the two specimens (XY-scan and Rot-scan) is not affected (Fig. $5 \mathrm{~d}-\mathrm{e}$ ). The low degree of $\sigma_{\mathrm{X}}$ relaxation following the baseplate removal suggests that most of the stress relaxation occurred after the thinning of the baseplate.

The $\sigma_{Y}$ maps for the Thin-Baseplate condition display points with RS values approaching the yield strength of the material $(806 \mathrm{MPa})$ in the case of

Y-scan and XY-scan specimens (Fig. 6a-c). The Y-scan specimen shows the highest $(850-700 \mathrm{MPa})$ values, and the Rot-scan specimen the lowest (750-600 MPa). In all the specimens, but particularly in the XY-scan and Rot-scan, the highest values tend to be localized at the tip region $(35-47 \mathrm{~mm})$.

The baseplate removal induces both an average relaxation of $200 \mathrm{MPa}$ in the XY-scan specimen and a reduction of the homogeneity of the stress distribution (Fig. 6d). The lowest values (400-500 MPa) are in this case observed in the tip region $(42-47 \mathrm{~mm})$. A central strip parallel to the X-direction exhibits the highest values $(600-750 \mathrm{MPa})$. This strip is asymmetric, and a small band of high values $(600-700 \mathrm{MPa})$ is observed connecting Surface 1 to the central strip between 35 and $40 \mathrm{~mm}$. The stress values in the rest of the specimen vary between 500 and $550 \mathrm{MPa}$. The baseplate removal also induces an 
average relaxation of about $200 \mathrm{MPa}$ in the Rot-scan specimen (Fig. 6e). The lowest values (400-500 MPa) are also observed at the tip region $(42-47 \mathrm{~mm})$, and the values in the rest of the specimen vary between 500 and $550 \mathrm{MPa}$. Note that neither the stress map in Fig. $6 \mathrm{c}$ nor the one in Fig. 6e shows traces of the two undulations observed in Fig. $4 \mathrm{~m}$. This indicates that the depth of the grooves induced by the hatching stripes is smaller than the depth $(42 \mu \mathrm{m}$ for 311 reflection) being probed by the $\mathrm{X}$-rays.

The $\sigma_{Z}$ values in the building direction on the lateral surface of the specimen (Surface 1) in the ThinBaseplate condition are quite homogeneous (see Fig. 7). Here, the tendency is inversed with respect to the Top Surface; whereby the Rot-scan specimen exhibits the highest values, which in some regions are higher than the bulk yield strength reported for the material. The lowest values $(600-700 \mathrm{MPa})$ are observed at the bottom of the specimen, where the prism is connected to the thin baseplate. The XY-scan specimen shows intermediate stress values between 500 and $600 \mathrm{MPa}$, and the Y-scan specimen has lower stresses between 450 and $500 \mathrm{MPa}$. In this Y-scan specimen, the lowest values are also observed at the bottom of the face.

The baseplate removal induces a $\sigma_{\mathrm{Z}}$ gradient from bottom to top in all the specimens. A relaxation of $300 \mathrm{MPa}$ is observed at the bottom of the Y-scan and $\mathrm{XY}$-scan specimens (Fig. 7e, f), although the values are barely relaxed at the top line. The stress relaxation is more significant near the bottom of the Rot-scan specimen $(450 \mathrm{MPa})$. When compared to the bottom measurement line, the stresses at the top line exhibit a lower degree of stress relaxation $(\sim 100 \mathrm{MPa})$.

The $\sigma_{X}$ maps of Surface 1 show values close to $0 \mathrm{MPa}$ for all three specimens in the Released (a)

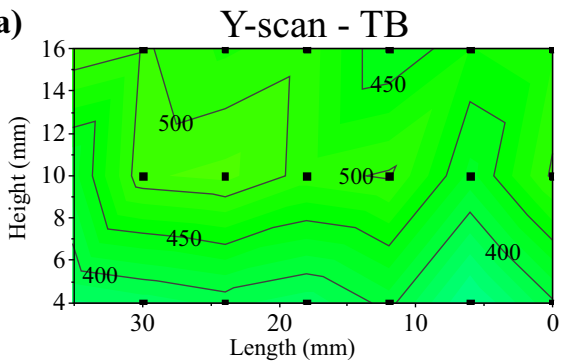

(b)

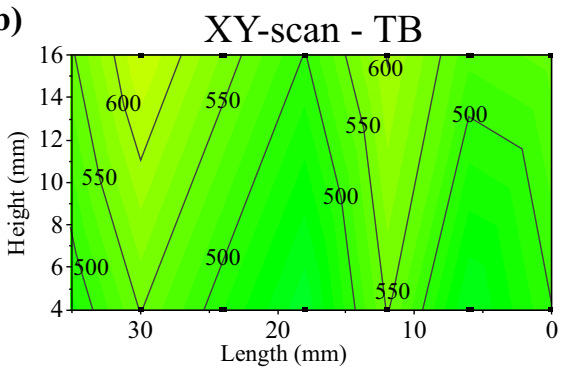

(c)

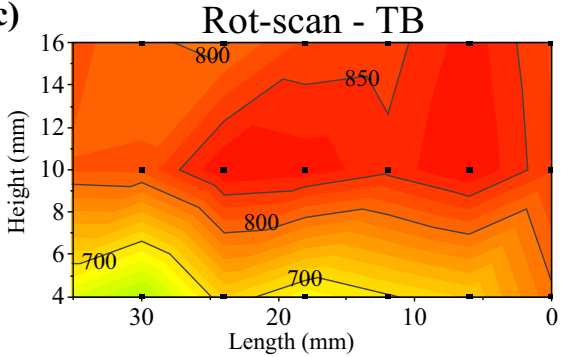

(d)

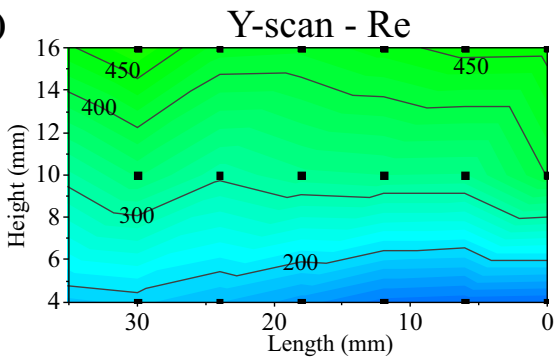

(e)

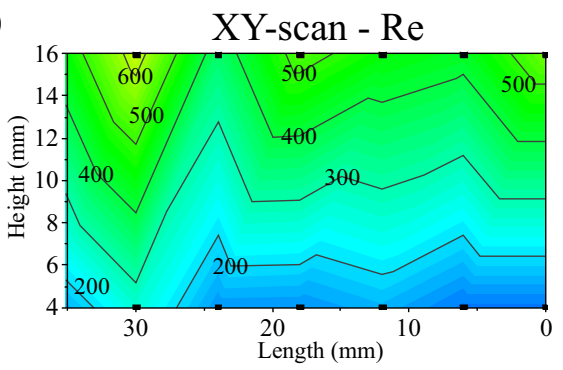

(f)

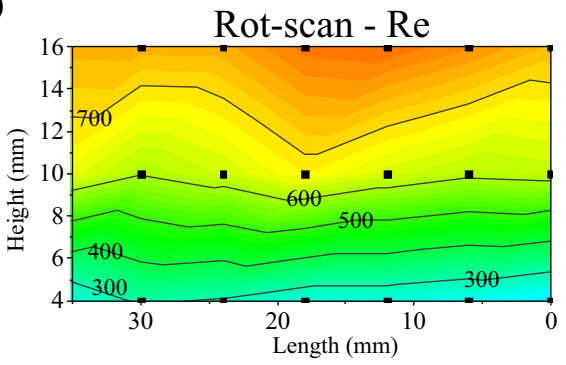

Figure 7 Surface 1 RS maps of the Z-direction component in the Thin-Baseplate (TB) condition for a the Y-scan specimen (replotted from [25]), b the XY-scan specimen (note that the intermediate points at $10 \mathrm{~mm}$ height are missing), and c the Rotscan specimen (replotted from [25]). Surface 1 RS maps of the
$\sigma_{\mathrm{Z}}(\mathrm{MPa})$
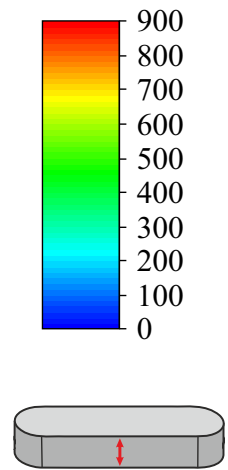

Z-direction component in the Released $(\mathrm{Re})$ condition for $\mathbf{d}$ the Y-scan specimen, e the XY-scan specimen (note that the intermediate points at $10 \mathrm{~mm}$ height are missing), and $\mathbf{f}$ the Rotscan specimen. The average error of the points shown in these maps is $\pm 27 \mathrm{MPa}$. 

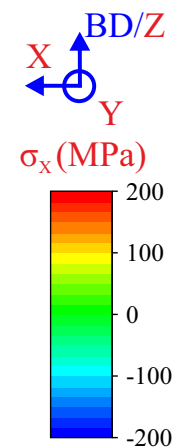

(a)
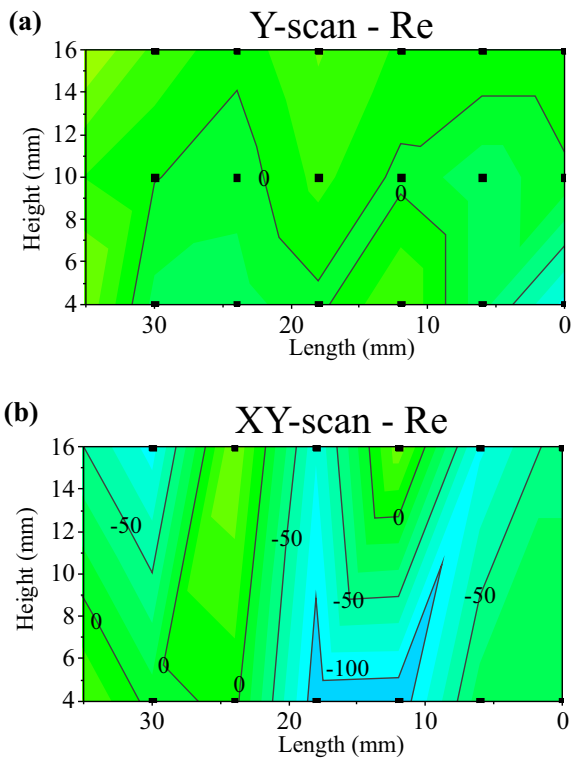

(c)

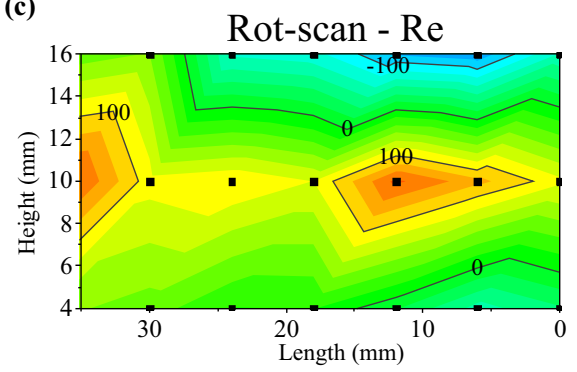

Figure 8 Surface 1 RS maps of the X-direction component in the Released (Re) condition for $\mathbf{a}$ the $\mathrm{Y}$-scan specimen, $\mathbf{b}$ the XY-scan specimen (note that the points at $10 \mathrm{~mm}$ height are missing), and c the Rot-scan specimen. The average error of the points shown in these maps is $\pm 26 \mathrm{MPa}$.

condition, particularly in the Y-scan specimen (see Fig. 8; note that the baseplate prevents the evaluation of the X-direction stress component in the ThinBaseplate condition because the $\mathrm{X}$-ray beam is blocked). The XY-scan specimen shows stresses close to $-100 \mathrm{MPa}$ at some point of the bottom and top measurement lines, which could be related to the distortion of the specimen. The Rot-scan specimen exhibits some points with compressive stresses at the top line (also close to $-100 \mathrm{MPa}$ ) and some points with tensile stresses (close to $150 \mathrm{MPa}$ ) at the central line at $10 \mathrm{~mm}$ height.

The $\sigma_{\mathrm{VM}}$ maps of Y-scan and XY-scan specimens in the Thin-Baseplate condition display similar stress levels (650-700 MPa) with some unevenly distributed localized regions containing higher values $(750 \mathrm{MPa}$, see Fig. 9a-c). The Rot-scan specimen shows overall lower values (500-650 MPa). The baseplate removal induces a similar effect on the XY-scan and Rot-scan specimens, with the most significant relaxation $(250 \mathrm{MPa})$ observed at the tip region $(42-47 \mathrm{~mm}$, Fig. $9 \mathrm{~d}-\mathrm{e}$ ). In the $0-40 \mathrm{~mm}$ region, an average stress reduction by $100 \mathrm{MPa}$ is observed in both XY-scan and Rot-scan specimens.

Even though the $\sigma_{\mathrm{VM}}$ maps indicate similar level of relaxation for the XY-scan and Rot-scan specimens, the distortion maps show considerable differences. The bending that followed the removal of the thinbaseplate is relatively low in the Y-scan and XY-scan specimens. However, the tendency is inverted in these two specimens when compared to that of Fig. 4h-i; the Y-scan specimen shows the highest Z-displacement values $(16 \mu \mathrm{m})$ in the region nearing the flat end of the specimen, while the XY-scan specimen shows the highest values at the tip $(22 \mu \mathrm{m})$. On the other hand, the Rot-scan specimen exhibits a considerably higher upward Z-displacement of the tip region $(Z=+150 \mu \mathrm{m})$. When the Released condition is compared to the As-Built one, the total $Z$-displacement occurring at the tip is about $Z=+240 \mu \mathrm{m}$.

\section{Surface roughness results}

The surface roughness results of the three specimens are summarized in Table 2. For the lateral Surface 1, the Rot-scan strategy exhibits the lowest surface roughness, while the Y-scanning displays the highest. The up-skin scanning strategy applied on the Top Surface is assumed to lead to similar roughness in the three specimens; thus, only the Top surface of XYscan sample was measured.

\section{Discussion}

\section{Influence of microstructure on diffraction measurements}

All $d_{\psi}^{311}-\sin ^{2} \psi$ plots of the EDXRD measurements displayed a linear dependence (Fig. 10, top graphs, where the average error is about $\pm 30 \mathrm{MPa}$ ). The lattice spacing versus $\sin ^{2} \psi$ plots show insignificant $\psi$-splitting [25] and, therefore, the absence of shear stresses is assumed.

The linearity of the $d_{\psi}^{311}-\sin ^{2} \psi$ plots indicates that the microstructure probed during the EDXRD measurements contains low texture and a reasonably 
(a)

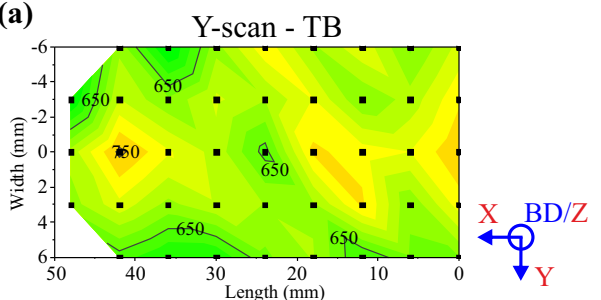

(b)
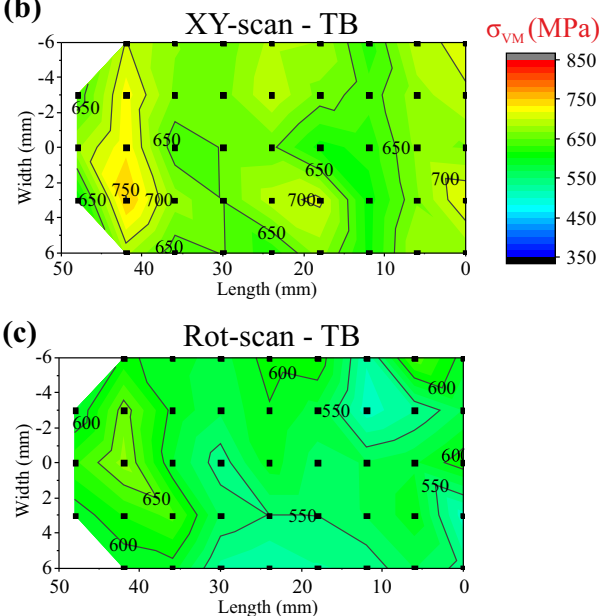

(d)

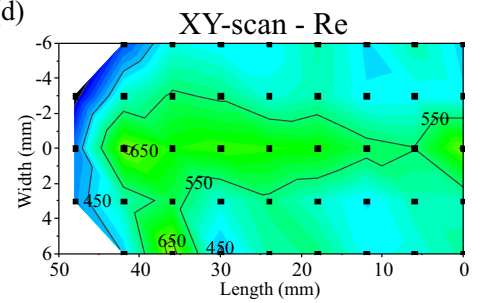

(e)

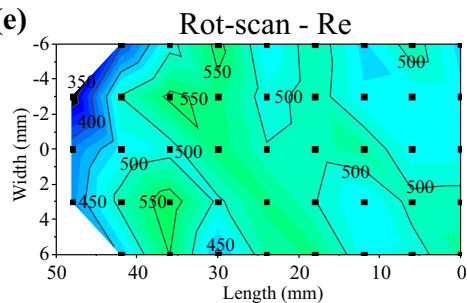

Released-Thin-Baseplate ( $\mu \mathrm{m})$

$\begin{array}{lllllllll}0 & 20 & 40 & 60 & 80 & 100 & 120 & 140 & 160\end{array}$

(f)

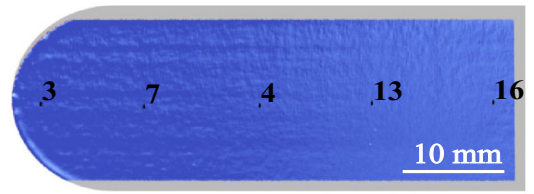

(g)

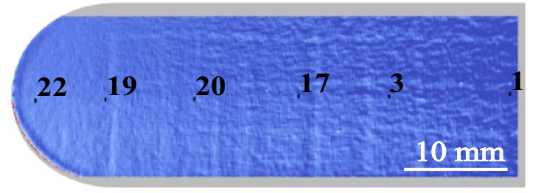

(h)

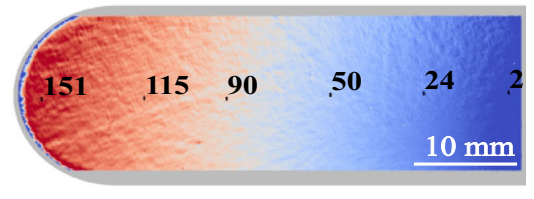

Figure 9 Top Surface maps of the Von Mises RS in the ThinBaseplate (TB) condition for $\mathbf{a}$ the Y-scan specimen, $\mathbf{b}$ the XYscan specimen, and $\mathbf{c}$ the Rot-scan specimen. Top Surface maps of the Von Mises RS in the Released (Re) condition for $\mathbf{d}$ the XY- scan specimen and $\mathbf{e}$ the Rot-scan specimen. Distortion maps showing the difference in Z-displacement between the ThinBaseplate and Released conditions for $\mathbf{f}$ the Y-scan specimen, $\mathbf{g}$ the $\mathrm{XY}$-scan specimen, and $\mathbf{h}$ the Rot-scan specimen.
Table 2 Summary of the surface roughness measured on the top and lateral surfaces (Surface 1)

\begin{tabular}{|c|c|c|c|c|c|c|}
\hline & \multicolumn{3}{|c|}{ Top Surface } & \multicolumn{3}{|l|}{ Surface 1} \\
\hline & $R_{\mathrm{a}}(\mu \mathrm{m})$ & $R_{\mathrm{z}}(\mu \mathrm{m})$ & $R_{\max }(\mu \mathrm{m})$ & $R_{\mathrm{a}}(\mu \mathrm{m})$ & $R_{\mathrm{z}}(\mu \mathrm{m})$ & $R_{\max }(\mu \mathrm{m})$ \\
\hline Y-scan & & & & $11.49 \pm 1.1$ & $71.7 \pm 9.8$ & $84.35 \pm 10.8$ \\
\hline XY-scan & $4.1 \pm 0.5$ & $22.0 \pm 3.8$ & $30.9 \pm 7.4$ & $9.43 \pm 1.0$ & $54.96 \pm 6.3$ & $74.7 \pm 12.4$ \\
\hline Rot-scan & & & & $4.52 \pm 1.1$ & $31.83 \pm 9.8$ & $39.8 \pm 14.2$ \\
\hline
\end{tabular}

small grain size. The integrated intensity of the diffraction peaks $\left(I_{\text {int }}=\int_{-\infty}^{\infty} I(2 \theta) \mathrm{d} 2 \theta\right)$ corroborates this statement, as it shows limited oscillations. Interestingly, the $I_{\text {int }}$ profiles are similar for all the investigated specimen surfaces. The integral breadth $\left.\left(\mathrm{IB}=\int I(2 \theta) \mathrm{d} 2 \theta\right) / I_{\max }\right)$, which depends on the orientation spread of the diffracting grains, on lattice intragranular strains, and on crystallite sizes, displays a similar tendency and values for all three specimens on the Top Surface. However, the Z-axis values on Surface 1 are observed to be systematically higher than the values measured at the Top Surface. Such an effect seems more related to the different grain sizes. In fact, EBSD investigations of the nearsurface regions of the Top Surface and of Surface 1
(Fig. 11) confirms the above conjecture. Significant differences in crystallite sizes and texture between the near-surface and bulk regions appear on all specimens. The up-skin grain structure is similar for all three specimens. The Y-scan specimen is given as an example of the near-surface grain structure: the difference between the Top surface and the bulk microstructure is more noticeable (Fig. 11a). The bulk columnar grain growth is halted at the up-skin border (dashed line in Fig. 11a). From this border upwards, new grains, usually spanning the entire upskin thickness are formed and both the texture intensity and the grain size are reduced.

On the other hand, the grain structures below Surface 1 exhibit a surface to bulk transition with 

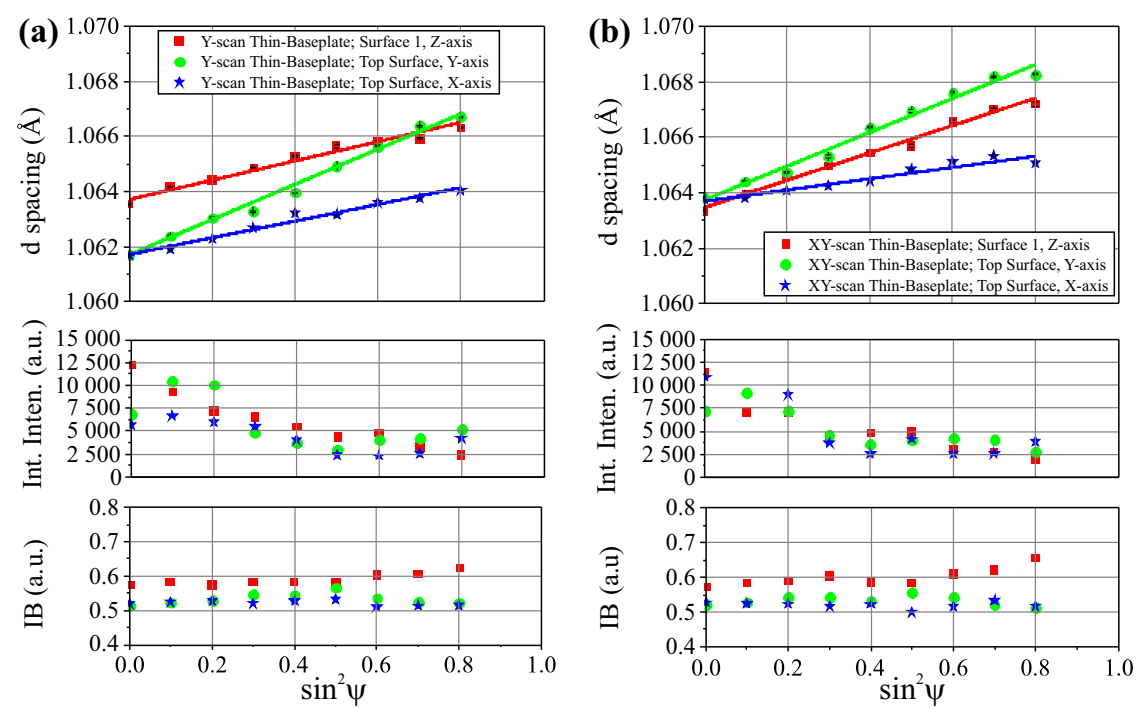
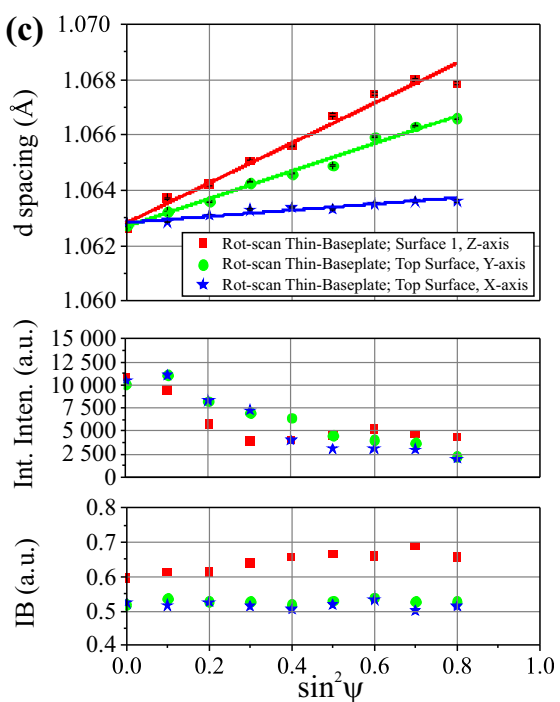

Figure 10 The $d_{\psi}^{311}-\sin ^{2} \psi$ linear regressions (top), the 311 Integrated Intensity (middle), and the 311 Integral Breadth (bottom) of the principal components (X-, Y-, and Z-directions)

significant differences between the specimens. In the Rot-scan specimen (Fig. 11b), there is a first layer below Surface 1 (thickness of $\sim 50 \mu \mathrm{m}$ ) containing close-to-equiaxed grains. Below this first layer, the grain structure resembles that of the bulk region shown in Fig. 3e. The grain structure of Y-scan specimen can be considered as tri-layered (Fig. 11c,d). The first layer below Surface 1 (of $\sim 150 \mu \mathrm{m}$ thickness) also contains relatively small grains. Next, a layer of $\sim 700 \mu \mathrm{m}$ thickness is formed, which exhibits $<001>$-grain orientation dominance and relatively larger columnar grains. From a depth of $850 \mu \mathrm{m}$ inwards, the microstructure shows features similar to those observed in the bulk region (Fig. 3c), i.e., larger columnar grains and $<101>$-grain orientation dominance. Interestingly, the first layer of small elongated grains seems not to be present in the XY-scan sample (Fig. 11e, f). Moreover, the transition between the second layer and the bulk microstructure (occurring at $\sim 700-800 \mu \mathrm{m}$ depth, and indicated with a white arrow in Fig. 11e) is less noticeable than in the Y-scan specimen.

Finally, it is noteworthy that the up-skin grains tend to be larger than the ones observed in the nearsurface of Surface 1 (Fig. 11), confirming that a smaller crystallite size seems to be the main reason behind the Top Surface-to-Surface 1 difference observed in the Integral Breadth plots (a gap of 0.1, Fig. 10). in the Thin-Baseplate condition for $\mathbf{a}$ the Y-scan specimen, $\mathbf{b}$ the $\mathrm{XY}$-scan specimen, and $\mathrm{c}$ the Rot-scan specimen.

\section{Influence of surface roughness on RS}

In general, an increased surface roughness is expected to lead to significantly lower RS magnitudes, as reported in the literature (e.g. [24]). As shown in Fig. 12, the RS state at the first measurement points (corresponding to the $\{111\}$ and $\{200\}$ families of lattice planes) at the Top Surface is not strongly affected by the surface roughness. However, the effect of surface roughness on the near-surface RS state of Surface 1 is clearly noticeable in the $0-45 \mu \mathrm{m}$ depth, where the stress values tend to progressively increase from the $\{111\}$ plane up to the $\{311\}$ plane. Note that the stress increase is more significant in the $\mathrm{Y}$-scan and XY-scan specimens (about $300 \mathrm{MPa}$ ) than in the Rot-scan specimen (about $150 \mathrm{MPa}$ ), in agreement with the higher surface roughness measured in these two specimens (Table 2). A plateau is reached in all specimens between the $\{311\}$ and $\{420\}$ planes, indicating that the RS measured in these depths $(45 \mu \mathrm{m}$ and deeper) are no longer influenced by the stress relieving effect of the surface roughness.

\section{Choice of DEC for residual stress analysis}

As mentioned in the Introduction, the microstructural and texture characteristics of AM material challenge the common procedures of RS analysis, particularly those using diffraction techniques. In the absence of experimental determination of DEC via 
Figure 11 EBSD orientation maps (the scattering vector is along the X-direction) of the near-surface regions for the cases of: a the Y-scan specimen below the Top Surface (the dashed black line indicates the approximate location of the border with the up-skin layers (also reported in [25]), $\mathbf{b}$ the Rot-scan specimen below Surface 1 (reported in [25]), c the Y-scan specimen (low magnification) below Surface 1 (note that the surface roughness is croppedout when setting the indexed region of interest), $\mathbf{d}$ a higher magnification of the Y-scan image shown in (c) (reported in [25]), e the XY-scan specimen (low magnification) below Surface 1 (the white arrow indicates the approximate border between the subsurface region, 150-850 $\mu \mathrm{m}$, and the bulk microstructure), and $\mathbf{f}$ a higher magnification on the XYscan specimen, which corresponds to a region outside of the zone shown in (e).
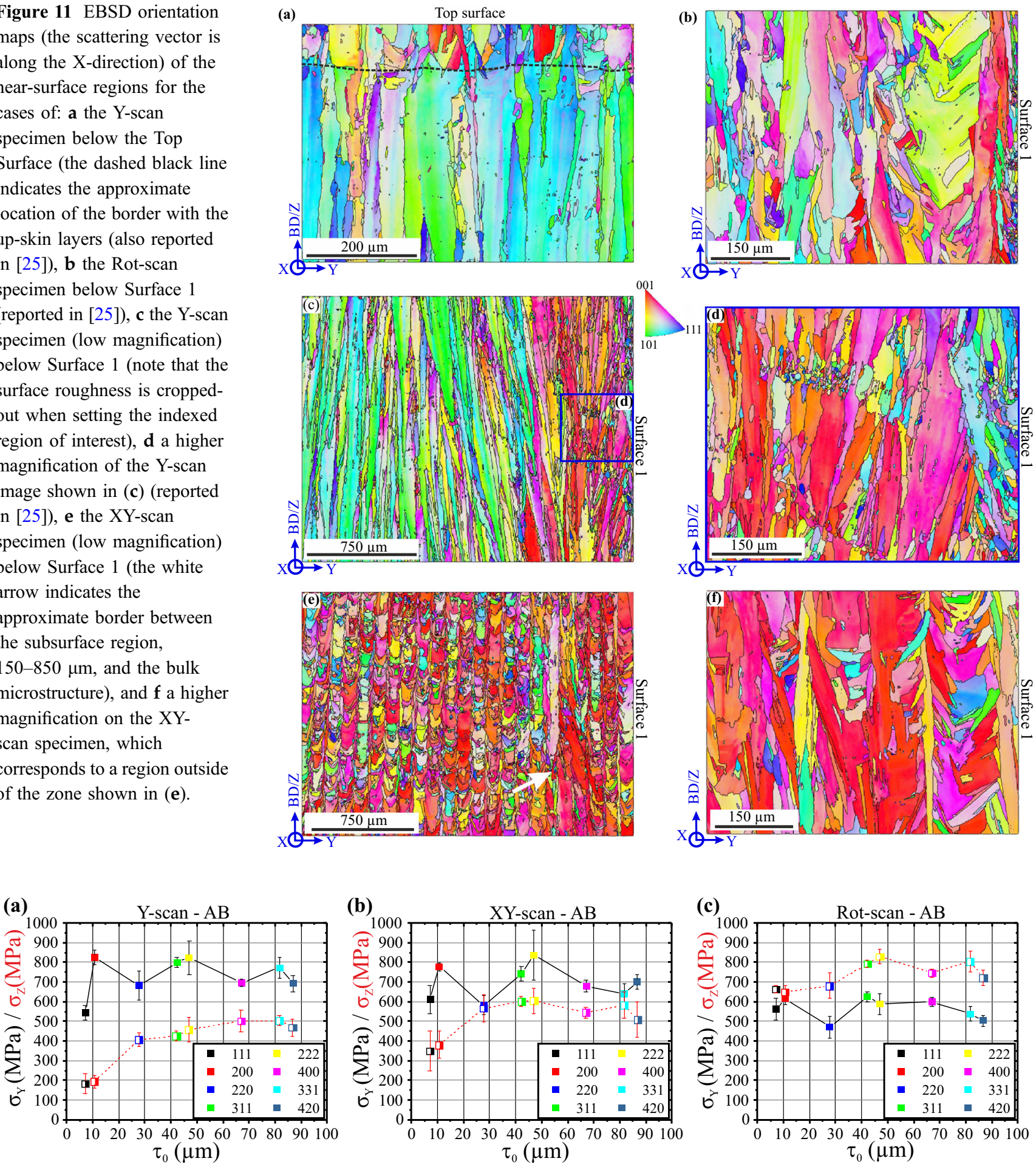

Figure 12 Depth profile plots corresponding to a point in the Top Surface (black solid line) and in Surface 1 (red dashed line) for a the Y-scan specimen (also reported in [25]), b the XY-scan specimen, and $\mathbf{c}$ the Rot-scan specimen (reported in [25]).

in situ loading tests, RS has been usually calculated in conventionally manufactured IN718 specimens using the Kröner model [31]. In the case of the present RS results, there are two main reasons that led to the application of the Reuß model instead of the Kröner model. The first issue when using the Kröner model arises from the high magnitude of the calculated RS. Using this model, near-surface residual stresses of 
magnitudes nearing $1200 \mathrm{MPa}$ are calculated, even though the bulk yield strength of the studied material varies between 632 and $806 \mathrm{MPa}$. Subsequent ageing heat-treatment processes can increase the yield strength up to $1200 \mathrm{MPa}$ through precipitation hardening [58]. However, SEM-BSE observations show that the characteristic interdendritic microsegregation of the as-manufactured microstructure is preserved in the near-surface, so that such a significant precipitation hardening should be excluded.

There are other factors that can locally increase the yield strength at the near surface. Given than the grain size is relatively smaller in the near-surface region compared to the bulk, a local increase in the yield strength could also be induced by the HallPetch effect. Moreover, a near-surface triaxial stress state, as is the case in composites, can also lead to magnitudes of residual stresses higher than the yield strength. However, the origin of such interphase, intergranular (Type II) stresses in the as-manufactured material is not obvious. High interphase stresses between the cell walls (where micro-segregation of alloying elements and high dislocation content at the subgrain boundaries occur) and the cell interior might be able to induce such triaxial state. This point would require further investigation using local techniques (i.e., focused ion beam-digital image correlation (FIB-DIC)) and cannot be taken as a fact here. Even if these effects (Hall-Petch and triaxiality) were combined, it is unlikely that they could induce an increase in the yield strength of about $400 \mathrm{MPa}$. As shown in Fig. 6a and b, the RS magnitudes calculated by the Reuß model are only slightly higher (maximum at $870 \mathrm{MPa}$ ) than the maximum bulk yield strength values. This slight increase seems much more realistic.

The high spikiness of the depth profiles (i.e., jumps between adjacent $\sigma\left(\tau_{0}^{\mathrm{hkl}}\right)$ values) also gives indication of the unsuitability of using the Kröner model for this material (Fig. 13a). The use of Reuß model has an effect of reducing this spikiness on the depth profiles, meaning that this model gives a more accurate description of the intergranular behaviour of the studied materials [43]. It is worth mentioning that in the present calculations the $\{331\}$ reflection is broadly model-independent, representing a fixed point that does not change its magnitude when the applied grain-integration model is changed.

A plot of the Young's moduli of some reflections against the stiffness anisotropy factor (denoted as $\left.\Gamma_{\mathrm{hkl}}=\left(\mathrm{h}^{2} \mathrm{k}^{2}+\mathrm{k}^{2} \mathrm{l}^{2}+\mathrm{l}^{2} \mathrm{~h}^{2}\right) /\left(h^{2}+k^{2}+l^{2}\right)^{2}\right)$ is given in Fig. 13b, where the Kröner and Reuß models are compared to experimental $E_{\mathrm{hkl}}$ data available in the literature for both conventional and $\mathrm{AM} \mathrm{Ni}$-base alloys [59-62]. Note that the Kröner model is suited for quasi-isotropic materials more typical of conventional processing, while the Reuß model seems suited to describe the textured microstructures of IN718 AM materials. One possible explanation for this observation is that in the case of highly textured materials, the crystallites could provide lower constraint to each other and can therefore expand more or less freely [63]; in other words, the columnar microstructure (see Fig. 3d, e) fits well to the ideal microstructure

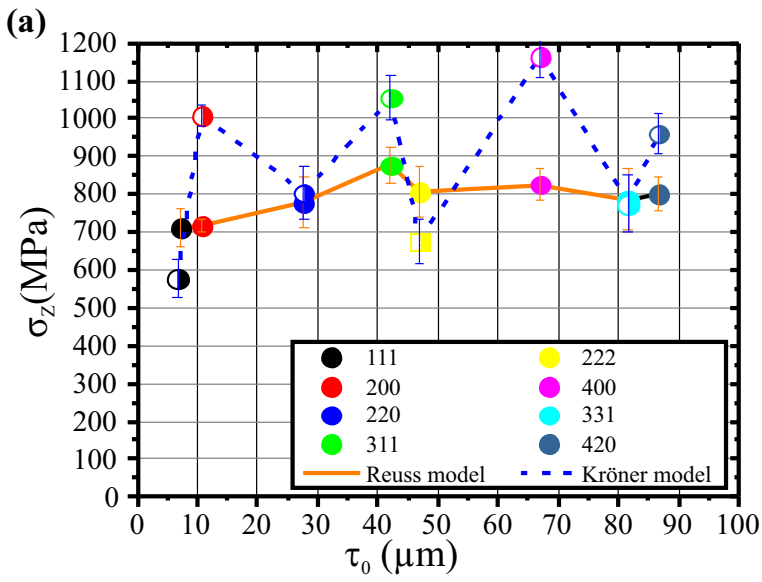

Figure 13 a Depth profile plot showing the differences between the use of the Kröner (blue dashed line) and the Reuß (orange solid line) models for DEC calculation in Surface 1 of the Rot-scan

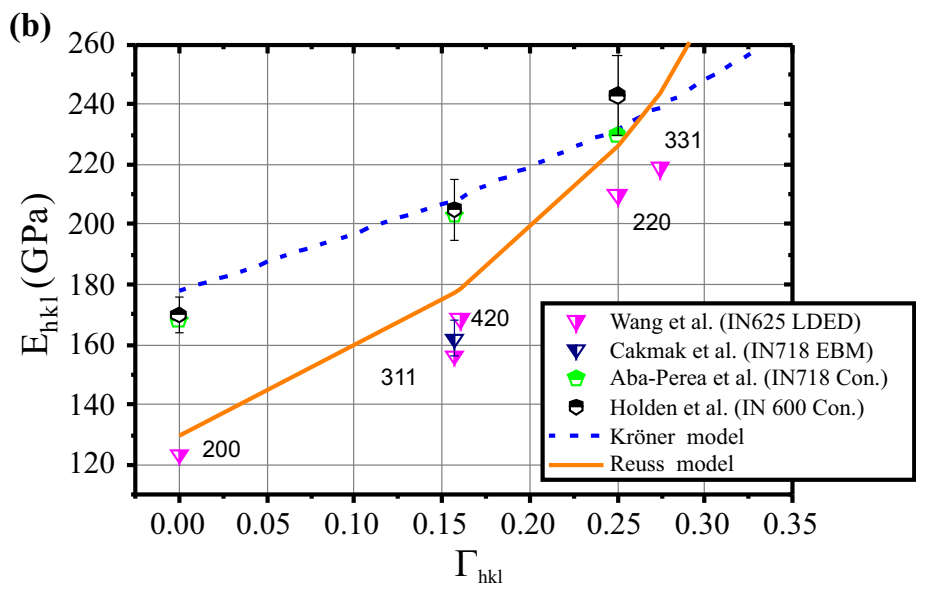

specimen. b Plot of Young's moduli of some reflections obtained from the literature [58-62] against the anisotropy factor $\Gamma_{\mathrm{hkl}}$ parallel to an applied uniaxial tensile stress. 
schematic of the Reuß model (parallel blocks undergoing the same applied stress).

Since Fig. 13a shows that the Reuß model leads to a lower scatter, it can be concluded that even the finer near-surface grains should also display significant texture effects. Further research is needed to determine if the models developed for materials with preferred texture (i.e., macroscopically anisotropic microstructures) can provide a better description of the IN718 AM intergranular behaviour.

\section{Considerations on the RS results}

The results presented in this study show a small asymmetry of the RS fields with respect to the X-axis (see Figs. 5 and 6). The direction of the inert gas flow is proposed as one of the factors that can contribute to the development of this asymmetry [24]. Hence, the influence of the gas flow on RS build-up is a topic of interest for future work.

It is also observed that the $\sigma_{X}$ component undergoes a significant relaxation after the baseplate thinning and all specimens exhibit some degree of bending. The removal of the specimen from the thin baseplate mainly relaxes the Z-direction component at the bottom of the lateral Surface 1, creating a stress gradient. As shown in Fig. 9, the XY-plane VM RS maps do not correlate to the degree of distortion observed upon removal from the thin baseplate. This suggests that a larger stress relaxation in the Z-direction most likely exerts the greatest influence on the higher distortion observed in the Rot-scan specimen (Fig. 9h).

There exists a tendency for the $\sigma_{X}$ and $\sigma_{Y}$ values on the Top Surface to decrease from the highest in the Y-scan specimen to the lowest in the Rot-scan specimen. This tendency is inversed on the lateral Surface 1 and the $\sigma_{Z}$ values decrease from the highest in the Rot-scan specimen to the lowest in the Y-scan specimen. The XY-scan strategy always sits between these other two. Using stress balance considerations, we can interpret the bulk behaviour using the nearsurface results. In fact, the lowest near-surface tensile $\sigma_{\mathrm{Z}}$ values measured on Surface 1 should translate into the lowest compressive bulk RS in the Y-scan specimen. In one of our previous works, we have shown that the bulk microstructure of the Y-scan specimen is suspected as the principal factor leading to the lower RS values in the Z-direction of this specimen [25]. It is predicated here that the Y-scan microstructure should be considered softer (i.e., due to a large grain size, it is easier to move and accumulate dislocations and subsequently relax RS) and less constrained (i.e., due to texture, the intergranular mismatch induced by the dislocation accumulation is less significant, subsequently leading to a reduced macroscopic plastic heterogeneity) than that of the Rot-scan specimen, where grain boundaries can more easily hinder dislocation movements. Furthermore, the grain structure and RS state of the XY-scan strategy appear to be between those observed in the Y-scan and Rot-scan strategies.

Before continuing with the rationalization of the differences in RS state observed in the three investigated specimens, a brief description on the prior knowledge in the formation of dislocation cell structure is due. Even though the mechanisms controlling dislocation generation during AM are still subjected to debate in the literature [64, 65], it is generally assumed that, independently of how they form, the periodic fluctuations in dislocation density are more stable than uniform arrays [66]. The spatial arrangement of the dislocation cell structure is controlled by the dendrite-cell geometries at the time of solidification [48]. During solidification, some geometrical necessary dislocations are formed at the cell walls to accommodate misorientations between dendrite arms. Also, the post-deposited material is subjected to thermal stresses induced by subsequent deposition passes. Thus, some dislocations would form at the dendrite cell interior, probably ending up entangled at the cell walls as a result of the ongoing thermal cycling. It follows that, presumably, the higher the thermal stresses induced by the processing, the higher the entanglement of dislocations. But how this entanglement affects the built-up of RS?

The role played by the grain structure, texture, as well as the thermal gradients on the built-up of RS is proposed to follow the schematics illustrated in Fig. 14. The grain structure is assumed to be similar in the XY-plane for all three samples (as far as the amount of grain boundaries is concerned, see, for example, Fig. 14a-c). Based on this assumption, all three microstructures would provide similar levels of constraint between the grains. In other words, the accumulation/entanglement of dislocations caused by plastic strain in the XY-plane should be similar in all three microstructures. In this case, we propose that the thermal gradient (TG) controls the build-up of RS in all three specimens (note that the situation 


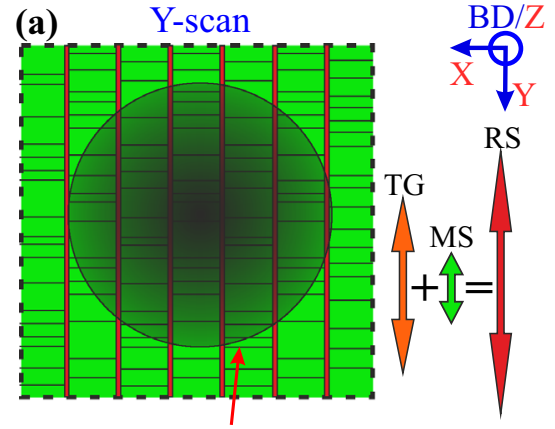

(d)

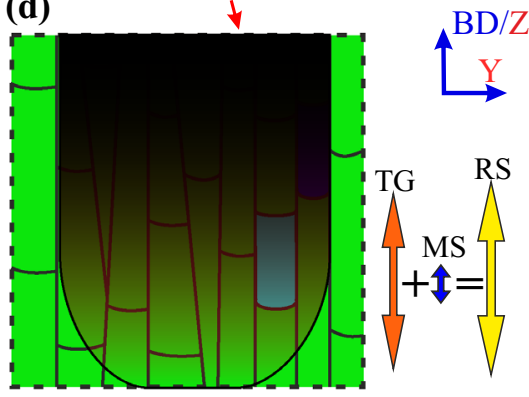

(b)

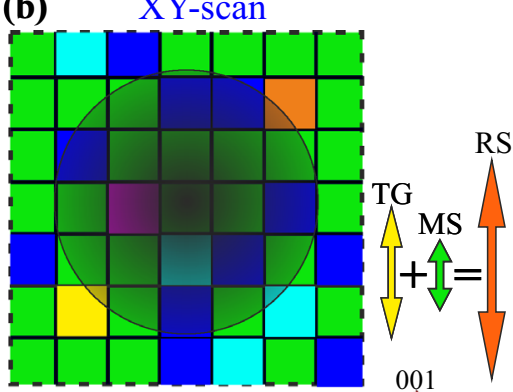

(e)

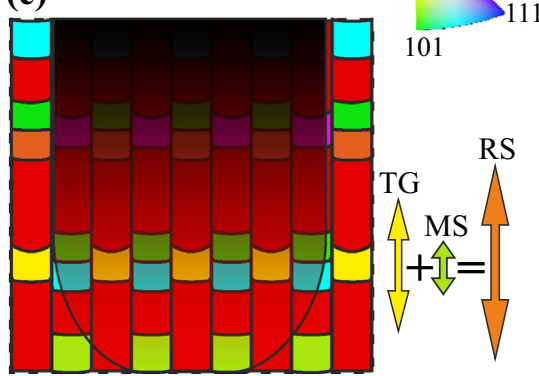

(c)

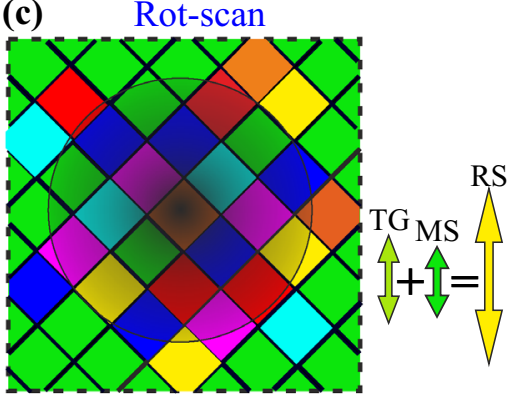

(f)

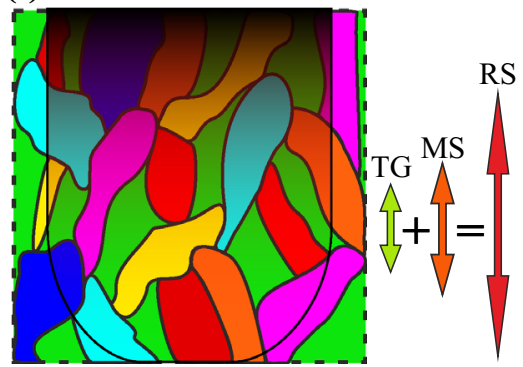

Figure 14 Schematic illustration of the effects of the bulk thermal gradients (TG, indicated with shaded areas) and microstructures (MS, with grain boundaries indicated by solid black lines and grain orientations following the colour code in the inset) on the residual stresses (RS) build-up occurring in the XY-plane of a the Y-scan

could be different in the early stages of cooling, where the microstructure does not possess its final features). However, this would not be the case in the ZY-plane, where the RS would notice the differences in microstructure (Fig. 14d-f). Due to smaller columnar grains and lower texture intensity than for the Y-scan strategy, the XY-scan microstructure would be expected to both increase the hindering of dislocation motion (i.e., to reduce the stress relaxation effects during processing) and induce higher intergranular stress mismatch. Finally, the Rot-scan specimen (for the same reasons) would be expected to have the lowest thermal gradient but the highest intergranular stress mismatch and lowest relaxation, thereby leading to the largest RS build-up. In summary, this assumption implies that the slip is activated in such a way that dislocations mainly propagate along the length ( $\mathrm{BD} / \mathrm{Z}$-axis) of the columnar/elongated grains [48].

It is noted that the shape of the thermal fields in Fig. 14 has been simplified in order to emphasize the differences between the presumed magnitudes of the gradients. The shapes and sizes of the thermal specimen, $\mathbf{b}$ the XY-scan specimen, and $\mathbf{c}$ the Rot-scan specimen; as well as in the ZY-plane of $\mathbf{d}$ the $\mathrm{Y}$-scan specimen, $\mathbf{e}$ the XY-scan specimen, and $\mathbf{f}$ the Rot-scan specimen. The size of the arrows indicates the intensity of each contributing factor.

gradients are expected to vary depending on the process parameters $[8,67]$.

Even though the above discussion is qualitative, it paves the road to future investigations. For instance, further assessment of the microstructural contribution to the RS built-up would require the use of neutron diffraction for the analysis of the bulk residual stresses and/or some local characterization using techniques such as FIB-DIC [68]. Additionally, comparison of the experimental results with finite element modelling of the process could help to further rationalize the relaxation mechanisms proposed here.

\section{Conclusions}

A comprehensive investigation of the influence of three different scanning strategies $(X, X Y$, and Rotation) on the resulting RS state and microstructure as well as on the distortion upon baseplate removal was performed by means of laboratory X-ray diffraction, synchrotron energy-dispersive diffraction, and electron microscopy techniques. The following conclusions can be drawn: 
1. The thinning of the baseplate mainly relaxes the $X$-direction component, $\sigma_{\mathrm{X}}$, also leading to the upward bending of specimens (i.e., along the build direction $\mathrm{Z}$ ).

2. The $X Y$-scan specimen shows intermediate RS values of $\sigma_{X}$ and $\sigma_{Y}$ at the Top Surface and of $\sigma_{Z}$ at the lateral surface (Surface 1), when compared to the Y-scan and Rot-scan specimens. At the Top Surface, the RS ( $\sigma_{X}$ and $\sigma_{Y}$ ) magnitudes are observed to be highest for the Y-scan specimen. At Surface 1, the RS $\left(\sigma_{Z}\right)$ magnitudes are highest for the Rot-scan specimen.

3. The stress relaxation upon Thin-Baseplate removal is more significant for $\sigma_{\mathrm{Z}}$ at Surface 1 , where a stress gradient in the Z-direction forms to comply with changed boundary conditions.

4. The specimens in the Released condition retain a considerable amount of RS, although the X-direction stress in the lateral surfaces practically vanishes.

5. The distortion in the Released condition is the highest for the Rot-scan specimen, likely induced by the higher $\sigma_{Z}$ values observed on the Surface 1 of this specimen.

6. The grain structures and intensity of texture observed in the bulk vary from specimen to specimen, although the interdendritic micro-segregation is considered similar in all specimens and regions investigated.

7. Finer grain sizes and lower texture in the nearsurface regions yield close-to-linear $\sin ^{2} \psi$-scans. Due to the up-skin processing, all three specimens show similar microstructures below the Top Surface. In contrast, the microstructure below Surface 1 varies with the scanning strategy.

8. The Reuß model for DEC calculation is considered more suited than the Kröner model to describe the intergranular behaviour of IN718 AM materials, since it yields more realistic RS values in this study and displays better agreement than Kröner for DEC experimental data reported in the literature on AM Ni-base alloys.

\section{Acknowledgements}

Gratitude is expressed to Manuela Klaus and Christoph Genzel (HZB, Berlin, Germany) for their expertise and scientific guidance during the synchrotron experiments at EDDI beamline, in BESSY II. Siemens AG Power and Gas, Berlin, Germany, is acknowledged for the production of the studied material. F. Falk and R. Saliwan-Neumann are acknowledged for his assistance during microscopy work. K. Zieger is also acknowledged for his contribution to the surface roughness measurements.

\section{Author contributions}

Conceptualization: All the authors worked on the content of the paper. Investigation: ISM, TF, TM, AU, and DA were involved in the synchrotron $\mathrm{X}$-ray energy-dispersive diffraction experiments and/or subsequent post-treatment of the acquired data. AK performed the laboratory XRD measurements. RH performed the distortion measurements. ISM analysed all the data and AE assisted with the rationalization. Writing-review and editing: ISM wrote and edited the manuscript, which was revised and commented by TM, AK, AE, and GB.

\section{Funding}

Open Access funding enabled and organized by Projekt DEAL.

\section{Compliance with ethical standards}

Conflict of interest The authors declare that there are no conflicts of interest in the work presented above.

Open Access This article is licensed under a Creative Commons Attribution 4.0 International License, which permits use, sharing, adaptation, distribution and reproduction in any medium or format, as long as you give appropriate credit to the original author(s) and the source, provide a link to the Creative Commons licence, and indicate if changes were made. The images or other third party material in this article are included in the article's Creative Commons licence, unless indicated otherwise in a credit line to the material. If material is not included in the article's Creative Commons licence and your intended use is not permitted by statutory regulation or exceeds the permitted use, you will need to obtain permission directly from the copyright holder. To view a copy of 
this licence, visit http://creativecommons.org/licen ses/by/4.0/.

\section{References}

[1] Reed RC (2006) The superalloys fundamentals and applications. the superalloys fundamentals and applications: 1 . Cambridge University Press, UK

[2] Herzog D, Seyda V, Wycisk E, Emmelmann C (2016) Additive manufacturing of metals. Acta Materialia 117:371. https://doi.org/10.1016/j.actamat.2016.07.019

[3] DebRoy T, Wei HL, Zuback JS, Mukherjee T, Elmer JW, Milewski JO, Beese AM, Wilson-Heid A, De A, Zhang W (2018) Additive manufacturing of metallic components Process, structure and properties. Prog Mater Sci 92:112. h ttps://doi.org/10.1016/j.pmatsci.2017.10.001

[4] Wei HL, Mazumder J, DebRoy T (2015) Evolution of solidification texture during additive manufacturing. Sci Rep 5:16446. https://doi.org/10.1038/srep16446

[5] Sun S-H, Hagihara K, Nakano T (2018) Effect of scanning strategy on texture formation in Ni-25 at .\%Mo alloys fabricated by selective laser melting. Mater and Des 140:307. h ttps://doi.org/10.1016/j.matdes.2017.11.060

[6] Antonysamy AA, Meyer J, Prangnell PB (2013) Effect of build geometry on the $\beta$-grain structure and texture in additive manufacture of Ti6A14V by selective electron beam melting. Mater Charact 84:153. https://doi.org/10.1016/j.ma tchar.2013.07.012

[7] Tian Y, McAllister D, Colijn H, Mills M, Farson D, Nordin M, Babu S (2014) Rationalization of microstructure heterogeneity in INCONEL 718 builds made by the direct laser additive manufacturing process. Metall Mater Trans A 45:4470. https://doi.org/10.1007/s11661-014-2370-6

[8] Guevenoux C, Hallais S, Charles A, Charkaluk E, Constantinescu A (2020) Influence of interlayer dwell time on the microstructure of Inconel 718 laser cladded components. Optics and Laser Technol 128:106218. https://doi.org/10.10 16/j.optlastec.2020.106218

[9] Mercelis P, Kruth JP (2006) Residual stresses in selective laser sintering and selective laser melting. Rapid Prototyp J 12:254. https://doi.org/10.1108/13552540610707013

[10] Brandl E, Schoberth A, Leyens C (2012) Morphology, microstructure, and hardness of titanium (Ti-6Al-4V) blocks deposited by wire-feed additive layer manufacturing (ALM). Mater Sci Eng A 532:295. https://doi.org/10.1016/j.msea.2 011.10 .095

[11] Bartlett JL, Li X (2019) An overview of residual stresses in metal powder bed fusion. Addit Manuf 27:131. https://doi. org/10.1016/j.addma.2019.02.020
[12] Withers PJ, Bhadeshia HKDH (2001) Residual stress part 1 - measurement techniques. Mater Sci Technol 17:355. http s://doi.org/10.1179/026708301101509980

[13] Carpenter K, Tabei A (2020) On residual stress development, prevention, and compensation in metal additive manufacturing. Materials 13(2):255. https://doi.org/10.3390/ma 13020255

[14] Ahmad B, van der Veen SO, Fitzpatrick ME, Guo H (2018) Residual stress evaluation in selective-laser-melting additively manufactured titanium (Ti-6Al-4V) and inconel 718 using the contour method and numerical simulation. Addit Manuf 22:571. https://doi.org/10.1016/j.addma.2018.06.002

[15] Mishurova T, Cabeza S, Thiede T, Nadammal N, Kromm A, Klaus M, Genzel C, Haberland C, Bruno G (2018) The Influence of the support structure on residual stress and distortion in SLM inconel 718 parts. Metall Mater Trans A 49:3038. https://doi.org/10.1007/s11661-018-4653-9

[16] Thiede T, Cabeza S, Mishurova T, Nadammal N, Kromm A, Bode J, Haberland C, Bruno G (2018) Residual stress in selective laser melted inconel 718 influence of the removal from base plate and deposition hatch length. Mater Perform Charact 7:717. https://doi.org/10.1520/MPC20170119

[17] Parry L, Ashcroft IA, Wildman RD (2016) Understanding the effect of laser scan strategy on residual stress in selective laser melting through thermo-mechanical simulation. Addit Manuf 12:1. https://doi.org/10.1016/j.addma.2016.05.014

[18] Cheng B, Shrestha S, Chou K (2016) Stress and deformation evaluations of scanning strategy effect in selective laser melting. Addit Manuf 12:240. https://doi.org/10.1016/j.add ma.2016.05.007

[19] Robinson J, Ashton I, Fox P, Jones E, Sutcliffe C (2018) Determination of the effect of scan strategy on residual stress in laser powder bed fusion additive manufacturing. Addit Manuf 23:13. https://doi.org/10.1016/j.addma.2018.07.001

[20] Dimter M, Mayer R, Hümmeler L, Salzberger R, Kotila J, Syvänen T (2011) Method and device for manufacturing a three-Dimensional object. USA Patent US8034279B2

[21] Mumtaz K, Hopkinson N (2009) Top surface and side roughness of Inconel 625 parts processed using selective laser melting. Rapid Prototyp J 15:96. https://doi.org/10.11 08/13552540910943397

[22] Strano G, Hao L, Everson R, Evans K (2013) Surface roughness analysis, modelling and prediction in selective laser melting. J Mater Process Technol 213:589. https://doi. org/10.1016/j.jmatprotec.2012.11.011

[23] Calignano F (2018) Investigation of the accuracy and roughness in the laser powder bed fusion process. Virtual Phys Prototyp 13:97. https://doi.org/10.1080/17452759.201 8.1426368 
[24] Mishurova T, Artzt K, Haubrich J, Requena G, Bruno G (2019) Exploring the correlation between subsurface residual stresses and manufacturing parameters in laser powder bed fused Ti-6Al-4V. Metals 9:261. https://doi.org/10.3390/me t9020261

[25] Serrano-Munoz I, Mishurova T, Thiede T, Sprengel M, Kromm A, Nadammal N, Nolze G, Saliwan-Neumann R, Evans A, Bruno G (2020) The residual stress in as-built laser powder bed fusion IN718 alloy as a consequence of the scanning strategy induced microstructure. Sci Rep 10:14645. https://doi.org/10.1038/s41598-020-71112-9

[26] Noyan IC, Cohen JB (2013) Residual stress: measurement by diffraction and interpretation. Springer, New York

[27] Mishurova T, Artzt K, Haubrich J, Evsevleev S, Evans A, Meixner M, Serrano-Munoz I, Sevostianov I, Requena G, Bruno G (2020) Connecting diffraction-based strain with macroscopic stresses in laser powder bed fused Ti-6Al-4V. Metall Mater Trans A 51:3194. https://doi.org/10.1007/s11 661-020-05711-6

[28] Voigt W (1910) Lehrbuch der Kristallphysik. Teubner, Leipzig

[29] Reuss A (1929) Berechnung der fliessgrenze von mischkristallen auf grund der plastizitätsbedingung für einkristalle. ZAMM - J Appl Math Mech/Zeitschrift für Angewandte Mathematik und Mechanik 9:49. https://doi.or g/10.1002/zamm.19290090104

[30] Eshelby JD, Peierls RE (1957) The determination of the elastic field of an ellipsoidal inclusion, and related problems. In: Proceedings of the Royal Society of London. Series A. Mathematical and Physical Sciences, vol 241. The Royal Society, p 376. https://doi.org/10.1098/rspa.1957.0133

[31] Kröner E (1958) Berechnung der elastischen konstanten des vielkristalls aus den konstanten des einkristalls. J Zeitschrift für Physik 151:504. https://doi.org/10.1007/bf01337948

[32] Hauk V (1997) Structural and residual stress analysis by nondestructive methods: evaluation - application - assessment. Elsevier Science, Amsterdam

[33] Matthies S, Priesmeyer HG, Daymond MR (2001) On the diffractive determination of single-crystal elastic constants using polycrystalline samples. J Appl Crystallogr 34:585. h ttps://doi.org/10.1107/S0021889801010482

[34] Welzel U, Ligot J, Lamparter P, Vermeulen AC, Mittemeijer EJ (2005) Stress analysis of polycrystalline thin films and surface regions by X-ray diffraction. J. Appl. Crystallogr. 38:1. https://doi.org/10.1107/S0021889804029516

[35] Mishurova T, Bruno G, Evsevleev S, Sevostianov I (2020) Determination of macroscopic stress from diffraction experiments: a critical discussion. J Appl Phys 128:025103. https://doi.org/10.1063/5.0009101
[36] Deng D, Peng RL, Brodin H, Moverare J (2018) Microstructure and mechanical properties of Inconel 718 produced by selective laser melting: sample orientation dependence and effects of post heat treatments. Mater Sci Eng: A 713:294. https://doi.org/10.1016/j.msea.2017.12.043

[37] Schneider J, Lund B, Fullen M (2018) Effect of heat treatment variations on the mechanical properties of Inconel 718 selective laser melted specimens. Addit Manuf 21:248. h ttps://doi.org/10.1016/j.addma.2018.03.005

[38] Bachmann F, Hielscher R, Schaeben H (2011) Grain detection from $2 d$ and $3 d$ EBSD data-Specification of the MTEX algorithm. Ultramicroscopy 111:1720. https://doi.org/10.10 16/j.ultramic.2011.08.002

[39] Nadammal N, Kromm A, Saliwan-Neumann R, Farahbod L, Haberland C, Portella PD (2017) Influence of support configurations on the characteristics of selective laser-melted inconel 718. Jom 70:343. https://doi.org/10.1007/s11837-017-2703-1

[40] Genzel C, Denks IA, Gibmeier J, Klaus M, Wagener G (2007) The materials science synchrotron beamline EDDI for energy-dispersive diffraction analysis. Nucl Instru Methods Phys Res Sect A: Accel, Spectrom Detect Assoc Equip 578:23. https://doi.org/10.1016/j.nima.2007.05.209

[41] Genzel C, Denks IA, Klaus M (2012) Modern diffraction methods. https://doi.org/10.1002/9783527649884.ch5

[42] Dye D, Stone HJ, Reed RC (2001) Intergranular and interphase microstresses. Curr Opin Solid State Mater Sci 5:31. h ttps://doi.org/10.1016/S1359-0286(00)00019-X

[43] Klaus M, Genzel C (2019) Reassessment of evaluation methods for the analysis of near-surface residual stress fields using energy-dispersive diffraction. J Appl Crystallogr 52:94. https://doi.org/10.1107/S1600576718018095

[44] Apel D, Genzel M, Meixner M, Boin M, Klaus M, Genzel C (2020) EDDIDAT: a graphical user interface for the analysis of energy-dispersive diffraction data. J Appl Crystallogr 53:42. https://doi.org/10.1107/S1600576720005506

[45] Bertram A, Glüge R (2015) Solid mechanics: theory, modeling, and problems. Springer International Publishing, NW

[46] DIN EN ISO 4287:2010-07 Geometrical Product Specifications (GPS) - Surface texture: Profile method - Terms, definitions and surface texture parameters (2010).

[47] Huang W, Yang J, Yang H, Jing G, Wang Z, Zeng X (2019) Heat treatment of Inconel 718 produced by selective laser melting: microstructure and mechanical properties. Mater Sci Eng: A 750:98. https://doi.org/10.1016/j.msea.2019.02.046

[48] Gallmeyer TG, Moorthy S, Kappes BB, Mills MJ, AminAhmadi B, Stebner AP (2020) Knowledge of processstructure-property relationships to engineer better heat treatments for laser powder bed fusion additive manufactured Inconel 718. Addit Manuf 31:100977. https://doi.org/ 10.1016/j.addma.2019.100977 
[49] Chlebus E, Gruber K, Kuźnicka B, Kurzac J, Kurzynowski T (2015) Effect of heat treatment on the microstructure and mechanical properties of Inconel 718 processed by selective laser melting. Mater Sci Eng: A 639:647. https://doi.org/10. 1016/j.msea.2015.05.035

[50] Zhang D, Niu W, Cao X, Liu Z (2015) Effect of standard heat treatment on the microstructure and mechanical properties of selective laser melting manufactured Inconel 718 superalloy. Mater Sci Eng: A 644:32. https://doi.org/10.101 6/j.msea.2015.06.021

[51] Brenne F, Taube A, Pröbstle M, Neumeier S, Schwarze D, Schaper M, Niendorf T (2016) Microstructural design of Nibase alloys for high-temperature applications: impact of heat treatment on microstructure and mechanical properties after selective laser melting. Prog Addit Manuf 1:141. https://doi. org/10.1007/s40964-016-0013-8

[52] Aydinöz ME, Brenne F, Schaper M, Schaak C, Tillmann W, Nellesen J, Niendorf T (2016) On the microstructural and mechanical properties of post-treated additively manufactured Inconel 718 superalloy under quasi-static and cyclic loading. Mater Sci Eng: A 669:246. https://doi.org/10.1016/ j.msea.2016.05.089

[53] Hilaire A, Andrieu E, Wu X (2019) High-temperature mechanical properties of alloy 718 produced by laser powder bed fusion with different processing parameters. Addit Manuf 26:147. https://doi.org/10.1016/j.addma.2019.01.012

[54] Tucho WM, Cuvillier P, Sjolyst-Kverneland A, Hansen V (2017) Microstructure and hardness studies of Inconel 718 manufactured by selective laser melting before and after solution heat treatment. Mater Sci Eng: A 689:220. https://d oi.org/10.1016/j.msea.2017.02.062

[55] Li X, Shi JJ, Wang CH, Cao GH, Russell AM, Zhou ZJ, Li CP, Chen GF (2018) Effect of heat treatment on microstructure evolution of Inconel 718 alloy fabricated by selective laser melting. J Alloys and Compd 764:639. http s://doi.org/10.1016/j.jallcom.2018.06.112

[56] Yoo YSJ, Book TA, Sangid MD, Kacher J (2018) Identifying strain localization and dislocation processes in fatigued Inconel 718 manufactured from selective laser melting. Mater Sci Eng: A 724:444. https://doi.org/10.1016/j.msea. 2018.03.127

[57] Zhou L, Mehta A, McWilliams B, Cho K, Sohn Y (2019) Microstructure, precipitates and mechanical properties of powder bed fused inconel 718 before and after heat treatment. J Mater Sci Technol 35:1153. https://doi.org/10.1016/j. jmst.2018.12.006

[58] Hosseini E, Popovich VA (2019) A review of mechanical properties of additively manufactured Inconel 718. Addit Manuf 30:100877. https://doi.org/10.1016/j.addma.2019. 100877
[59] Wang Z, Denlinger E, Michaleris P, Stoica AD, Ma D, Beese AM (2017) Residual stress mapping in Inconel 625 fabricated through additive manufacturing: method for neutron diffraction measurements to validate thermomechanical model predictions. Mater Des 113:169. https://doi.org/10.1 016/j.matdes.2016.10.003

[60] Cakmak E, Kirka MM, Watkins TR, Cooper RC, An K, Choo H, Wu W, Dehoff RR, Babu SS (2016) Microstructural and micromechanical characterization of IN718 theta shaped specimens built with electron beam melting. Acta Materialia 108:161. https://doi.org/10.1016/j.actamat.2016.02.005

[61] Aba-Perea PE, Pirling T, Withers PJ, Kelleher J, Kabra S, Preuss M (2016) Determination of the high temperature elastic properties and diffraction elastic constants of Ni-base superalloys. Mater Des 89:856. https://doi.org/10.1016/j.ma tdes.2015.09.152

[62] Holden TM, Holt RA, Clarke AP (1998) Intergranular strains in Inconel-600 and the impact on interpreting stress fields in bent steam-generator tubing. Mater Sci Eng: A 246:180. h ttps://doi.org/10.1016/S0921-5093(97)00732-6

[63] Spiess L, Teichert G, Schwarzer R, Behnken H, Genzel C (2009) Moderne Röntgenbeugung: Röntgendiffraktometrie für Materialwissenschaftler, Physiker und Chemiker, on page 377. Vieweg+Teubner Verlag. https://doi.org/10.1007/9783-8349-9434-9

[64] Birnbaum AJ, Steuben JC, Barrick EJ, Iliopoulos AP, Michopoulos JG (2019) Intrinsic strain aging, $\Sigma 3$ boundaries, and origins of cellular substructure in additively manufactured 316L. Addit Manuf 29:100784. https://doi.or g/10.1016/j.addma.2019.100784

[65] Shamsujjoha M, Agnew SR, Fitz-Gerald JM, Moore WR, Newman TA (2018) High strength and ductility of additively manufactured 3161 stainless steel explained. Metall Mater Trans A 49:3011. https://doi.org/10.1007/s11661-018-46072

[66] Holt DL (1970) Dislocation cell formation in metals. J Appl Phys 41:3197. https://doi.org/10.1063/1.1659399

[67] Wei HL, Knapp GL, Mukherjee T, DebRoy T (2019) Threedimensional grain growth during multi-layer printing of a nickel-based alloy Inconel 718. Addit Manuf 25:448. http s://doi.org/10.1016/j.addma.2018.11.028

[68] Lunt Aj G, Korsunsky AM (2014) Intragranular residual stress evaluation using the semi-destructive FIB-DIC ringcore drilling method. Adv Mater Res 996:8. https://doi.org/ 10.4028/www.scientific.net/AMR.996.8

Publisher's Note Springer Nature remains neutral with regard to jurisdictional claims in published maps and institutional affiliations. 